\title{
Hydrogen bonding of formamide, urea, urea monoxide and their thio-analogs with water and homodimers
}

\author{
DAMANJIT KAUR* and SHWETA KHANNA \\ Department of Chemistry, Guru Nanak Dev University, Amritsar 143 005, India \\ e-mail: damanjit32@yahoo.co.in
}

MS received 11 January 2014; revised 27 May 2014; accepted 29 May 2014

\begin{abstract}
Ab initio and DFT methods have been employed to study the hydrogen bonding ability of formamide, urea, urea monoxide, thioformamide, thiourea and thiourea monoxide with one water molecule and the homodimers of the selected molecules. The stabilization energies associated with the monohydrated adducts and homodimers' formation were evaluated at B3LYP/6-311++G** and MP2/6-311++G** levels. The energies were corrected for zero-point vibrational energies and basis set superposition error using counterpoise method. Atoms in molecules study has been carried out in order to characterize the hydrogen bonds through the changes in electron density and laplacian of electron density. A natural energy decomposition and natural bond orbital analysis was performed to understand the nature of hydrogen bonding.
\end{abstract}

Keywords. Hydrogen bonding; stabilization energy; AIM; NEDA; NBO.

\section{Introduction}

Intermolecular interactions like van der Waals or hydrogen bonding have drawn attention of many scientific groups due to their importance in physical, chemical and biological fields. ${ }^{1-4}$ Formamide-water complex provides the simplest model for the hydration of proteins. Due to the simplicity of this model, it has been subjected to a large number of theoretical and experimental studies. ${ }^{5-17}$ Formamide-water complex also plays an essential role in the properties of various materials such as synthetic polymers, biomolecules, molecular solids and fluids. ${ }^{18-21}$ Urea and thiourea are widely used in the production of some pharmaceuticals (sulfothiazoles, barbiturates) and as an additive to some plastic materials. ${ }^{22}$ Zhang et al. used radial distribution functions, statistics of hydrogen bonding networks and the viscosities to study the interactions and structures of urea-water system by an all-atom molecular dynamics simulation. They concluded that urea molecule shows the tendency to self-aggregate with increasing mole fraction of urea. ${ }^{23}$ Many theoretical and experimental investigations performed on this urea-water system. ${ }^{24-35}$ The stabilities of thiourea-water complexes were investigated theoretically as well. ${ }^{36}$

Thiourea and its oxides were extensively used in various industrial productions such as in photosensitive materials, medicine, spices and the recycle of precious

\footnotetext{
*For correspondence
}

metals. $^{37-41}$ The Jacobsen group made the most remarkable advances in the domain of urea and thiourea catalysts. ${ }^{42}$ Thiourea and thiourea oxides are also valuable for fundamental scientific researches, especially in the study of non-linear reaction dynamics. ${ }^{43}$ The studies on the kinetics and mechanisms of thiourea oxidation have attracted a great deal of attention. ${ }^{44,45}$ These investigations have led to a general conclusion that the oxidation of thiourea goes through S-oxygenation to form sulfenyl, sulfinic and sulfonic acids and finally sulfate ions. The R-naphthylthiourea and phenylthiourea are pulmonary toxins to rats. Thiourea causes liver and thyroid tumors in rats. ${ }^{46,47}$ Theoretical study on interactions between thiourea monoxide and water has been carried out to understand its stability in water. ${ }^{48}$

A variety of experimental and theoretical methods have been used to study the hydrogen bonding of homodimers. Formamide homodimers is important as a simple model for establishing the characteristics of $\mathrm{N}-\mathrm{H} \cdots \mathrm{O}=\mathrm{C}$ interaction present in a wide variety of biological systems. ${ }^{49-51}$ These interactions have been studied by both theoretical and experimental methods. ${ }^{52-60}$ For comparisons, the analysis of similar homodimers in case of thioformamide have also been studied. ${ }^{60}$ Several groups have studied urea homodimer interactions theoretically. ${ }^{61-64}$ The formation of urea homodimers and higher aggregates was confirmed from osmotic pressure measurements ${ }^{65}$ and some evidence of urea homodimer pairing in solution emerged at higher concentrations emerged from X-ray study. ${ }^{66}$ Present study systematically investigates the hydrogen bonding 
interactions that plays a significant role in stabilizing the monohydrated adducts of formamide, urea, urea monoxide, thioformamide, thiourea and thiourea monoxide with the aid of AIM, NEDA and NBO analysis. In this work, we have also conducted ab initio and DFT studies of the interaction in formamide, urea, urea monoxide, thioformamide, thiourea and thiourea monoxide homodimers.

\section{Computational Details}

All the calculations carried out with the Gaussian 09 package. ${ }^{67}$ The theoretical methods employed were Density Functional Theory (DFT) and ab initio molecular orbital method. ${ }^{68,69}$ The geometries of isolated formamide (F), urea (U), urea monoxide (UO), thioformamide (TF), thiourea (TU) and thiourea monoxide (TUS) and their corresponding 1:1 water adducts have been fully optimized at B3LYP/6-311++ $\mathrm{G}^{* *}$ [L1] and MP2/6-311++G** [L2] levels (geometrical parameters are given in supplementary information TS1-TS22). The optimized orientations of the adducts of the molecule with water obtained at MP2/6$311++\mathrm{G}^{* *}$ [L2] level are shown in figure 1. The homodimers of selected molecules were also optimized using above-mentioned theoretical methods. The geometrical parameters of optimized homodimers are reported in supplementary information TS23-TS38. The stabilization energy $(\Delta \mathrm{E})$ calculated as the difference of the total energy of the monohydrated adducts or homodimers and the sum of the isolated monomers in their minima configurations. The zero-point vibrational energy (ZPE) with basis set superposition error (BSSE) corrected stabilization energy $\left(\Delta \mathrm{E}_{\text {Corr }}\right)$ for all of the monohydrated adducts and homodimers were calculated at B3LYP/6-311++G**[L1] and MP2/6$311++\mathrm{G}^{* *}$ [L2] levels. The counterpoise method proposed by Boys and Bernardi used to estimate the BSSE. $^{70}$

The scaling factor of 0.96 and 0.95 was used for ZPE at B3LYP/6-311++ $\mathrm{G}^{* *}[\mathbf{L} 1]$ and MP2/6-311++G** [L2] levels respectively. ${ }^{71}$ The atoms in molecules (AIM) calculations were performed using the AIM2000 program. ${ }^{72,73}$ The natural energy decomposition analysis (NEDA) $)^{74-76}$ calculations were performed with the NBO 5.9 $9^{77,78}$ program linked to the GAMESS ${ }^{79}$ package. A natural bond orbital (NBO) analysis were carried out using the NBO package included in the Gaussian 09 suite of programs. ${ }^{80,81}$ The geometrical parameters and $\Delta \mathrm{E}_{\text {Corr }}$ values obtained at MP2/6-311++ $\mathrm{G}^{* *}$ [L2] level are considered for discussion unless and otherwise mentioned.

\section{Results and Discussion}

\subsection{AIM analysis}

The analysis of topology of electron density using AIM has been used extensively to locate the hydrogen bonds. The values of electron density $(\rho)$ at bond critical point $(\mathrm{BCP})$ and its laplacian $\left(\nabla_{\rho}^{2}\right)$ are important quantities to characterize hydrogen bond's strength and its nature. The value of topological properties at BCPs characterizing the hydrogen bonds in monohydrate adducts and homodimers are reported in supplementary information table TS39-TS40. The $\rho$ values at BCP in monohydrate adducts for molecules containing oxygen are in the range 0.014-0.042 au and the similar range for the monohydrate adducts of thioanalogs is $0.008-0.035$ au. Relatively lower range of $\rho$ values point towards the comparatively weak nature of hydrogen interactions in latter adducts. The $\nabla_{\rho}^{2}$ indicating whether the electron density is locally concentrated $\left(\nabla_{\rho}^{2}<0\right)$ or depleted $\left(\nabla_{\rho}^{2}>0\right)$ for all the hydrogen bonded monohydrate adducts shown in table TS39 range from $0.052-0.160$ au and from $0.020-0.104$ au for oxo- and thio-adducts, respectively. The values for $\nabla_{\rho}^{2}$ are clearly positive, as expected for the hydrogen bond. For homodimers of molecules containing oxygen $\rho$ values at BCPs falls in the range of 0.011-0.032 au, whereas homodimers of thio-analogs falls in the range of $0.010-0.028 \mathrm{au}$ and the values of $\nabla^{2} \rho$ at the BCPs are positive and well within the range suggested for hydrogen bonds (table TS40). The $\rho$ and $\nabla_{\rho}^{2}$ at BCP are smaller for the $\mathrm{H} \cdots \mathrm{S}$ bonds than that for $\mathrm{H}$. . O bonds in monohydrated adducts and homodimers. These values of $\rho$ and $\nabla_{\rho}^{2}$ fall within the range specified for the existence of the hydrogen bond in terms of $\rho(0.002-$ $0.040 \mathrm{au})$ and its $\nabla_{\rho}^{2}(0.024-0.139 \mathrm{au})$ as suggested by Koch and Popelier with a few exceptions. ${ }^{82,83}$

\subsection{Important structural changes and stabilization energies}

Full geometrical optimizations of formamide, urea, urea monoxide, thioformamide, thiourea and thiourea monoxide and their adducts with single water have been carried out at B3LYP/6-311++G** [L1] and MP2/6$311++\mathrm{G}^{* *}[\mathbf{L} 2]$ theoretical levels. The hydrogen bond distances and angles at the bridging hydrogen along with the stabilization energies are recorded in table 1. It was observed that the stabilization energies evaluated at MP2/6-311++ $\mathrm{G}^{* *}$ [L2] level fall in the range of 2.73$9.29 \mathrm{kcal} / \mathrm{mol}$ and are consistently lower than the values obtained at B3LYP/6-311++ $\mathrm{G}^{* *}$ [L1] which fall in the range of $3.64-10.54 \mathrm{kcal} / \mathrm{mol}$ theoretical level. 


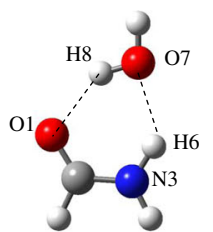

$\mathrm{FW}_{1}$

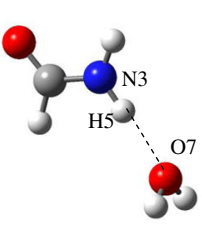

$\mathrm{FW}_{2}$

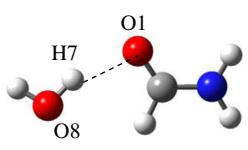

$\mathrm{FW}_{3}$

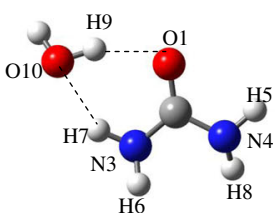

$\mathbf{U W}_{1}$

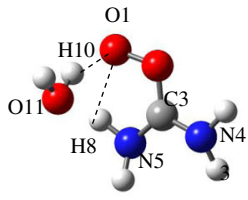

UOW $_{1}$

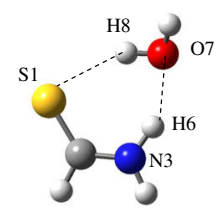

TFW $_{1}$
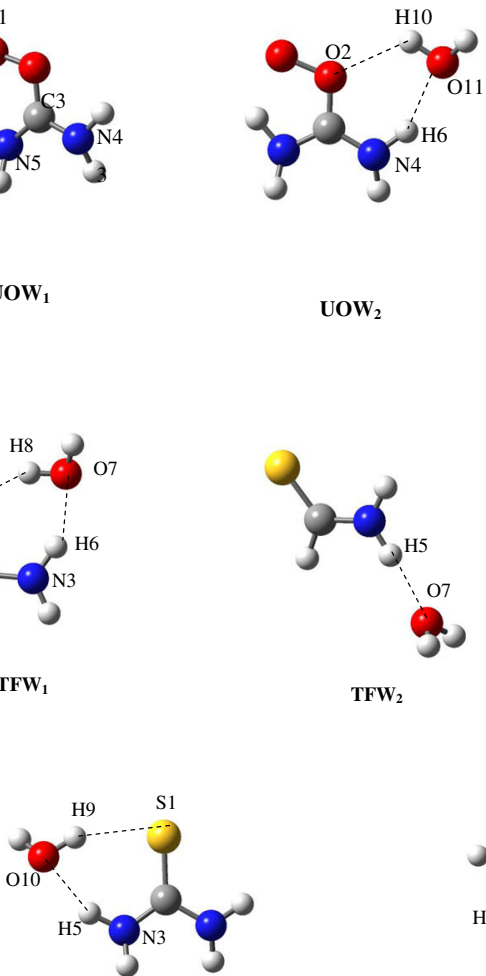

UOW $_{2}$

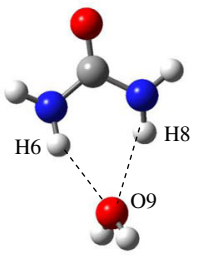

$\mathbf{U W}_{2}$

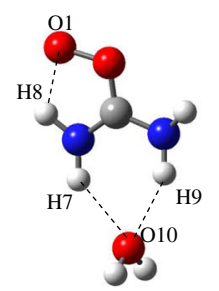

UOW $_{3}$

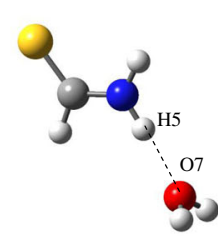

$\mathrm{TFW}_{2}$
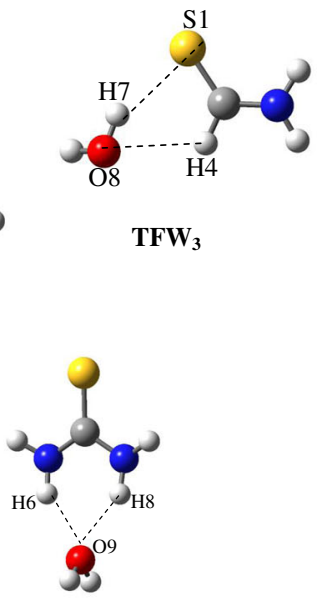

$\mathrm{TUW}_{2}$

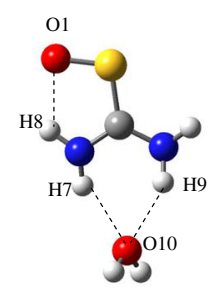

TUSW $_{2}$

Figure 1. The optimized hydrogen bonded adducts with water at MP2/6-311++G** [L2] level. 
Table 1. Hydrogen bond distances $(r)$ in $(\AA)$, angles in $\left(^{\circ}\right)$ important for hydrogen bonding interactions, difference of hydrogen bond distances from sum of vander Waals radii $(\Delta r)$ at MP2/6-311+ $+\mathrm{G}^{* *}[\mathbf{L 2}]$ level and stabilization energies $\left(\Delta \mathrm{E}_{\text {Corr }}\right)$ in $(\mathrm{kcal} / \mathrm{mol})$ for monohydrated adducts at B3LYP/6-311++G** [L1] and MP2/6-311++G** [L2] levels are obtained. $\mathrm{r}_{\mathrm{VW}} *$ (sum of van der Waals radii $)=\mathrm{r}_{\mathrm{O}}+\mathrm{r}_{\mathrm{H}}=2.6 \AA, \mathrm{r}_{\mathrm{H}}+\mathrm{r}_{\mathrm{S}}=3.05 \AA$.

\begin{tabular}{|c|c|c|c|c|c|c|c|}
\hline \multirow{4}{*}{$\begin{array}{l}\text { Adducts } \\
\text { FW }_{\mathbf{1}}\end{array}$} & \multirow{2}{*}{\multicolumn{2}{|c|}{$\begin{array}{l}\text { Hydrogen bond } \\
\text { distances(r) }\end{array}$}} & \multirow{4}{*}{$\begin{array}{c}\Delta \mathrm{r}=\mathrm{r}_{\mathrm{VW} *-} \mathrm{r} \\
0.653 \\
0.540\end{array}$} & \multirow{2}{*}{\multicolumn{2}{|c|}{$\begin{array}{l}\text { Hydrogen bonding } \\
\text { angles }\end{array}$}} & \multicolumn{2}{|c|}{$\Delta \mathrm{E}_{\text {Corr }}$} \\
\hline & & & & & & \multirow{3}{*}{$\begin{array}{c}\mathbf{L 1} \\
7.21\end{array}$} & \multirow{3}{*}{$\begin{array}{l}\mathbf{L 2} \\
6.34\end{array}$} \\
\hline & $\mathrm{O} 1 \cdots \mathrm{H} 8$ & 1.947 & & O1-H8-O7 & 145.30 & & \\
\hline & $\mathrm{O} 7 \cdots \mathrm{H} 6$ & 2.060 & & N3-H6-O7 & 136.40 & & \\
\hline \multirow[t]{2}{*}{ TFW $_{1}$} & $\mathrm{~S} 1 \cdots \mathrm{H} 8$ & 2.394 & 0.206 & S1-H8-O7 & 146.70 & \multirow[t]{2}{*}{6.81} & \multirow[t]{2}{*}{5.23} \\
\hline & $\mathrm{O} 7 \cdots \mathrm{H} 6$ & 1.940 & 0.660 & $\mathrm{H} 6-\mathrm{O} 7-\mathrm{H} 9$ & 135.85 & & \\
\hline $\mathrm{FW}_{2}$ & $\mathrm{O} 7 \cdots \mathrm{H} 5$ & 1.995 & 0.605 & $\mathrm{H} 5-\mathrm{O} 7-\mathrm{H} 8$ & 177.61 & 3.83 & 3.54 \\
\hline TFW $_{2}$ & $\mathrm{O} 7 \cdots \mathrm{H} 5$ & 1.961 & 0.639 & O7-H5-N3 & 176.57 & 4.52 & 3.85 \\
\hline $\mathrm{FW}_{3}$ & $\mathrm{O} 1 \cdots \mathrm{H} 7$ & 1.900 & 0.700 & $\mathrm{O} 1-\mathrm{H} 7-\mathrm{O} 8$ & 156.63 & 4.73 & 3.67 \\
\hline \multirow[t]{2}{*}{$\mathrm{TFW}_{3}$} & $\mathrm{~S} 1 \cdots \mathrm{H} 7$ & 2.390 & 0.660 & $\mathrm{~S} 1-\mathrm{H} 7-\mathrm{O} 8$ & 153.00 & \multirow[t]{2}{*}{3.64} & \multirow[t]{2}{*}{2.73} \\
\hline & $\mathrm{O} 8 \cdots \mathrm{H} 4$ & 2.520 & 0.080 & $\mathrm{H} 4-\mathrm{O} 7-\mathrm{H} 8$ & 145.74 & & \\
\hline \multirow[t]{2}{*}{$\mathbf{U W}_{1}$} & $\mathrm{O} 1 \cdots \mathrm{H} 9$ & 1.906 & 0.694 & O1-H9-O10 & 149.94 & \multirow[t]{2}{*}{7.51} & \multirow[t]{2}{*}{6.68} \\
\hline & $\mathrm{O} 10 \cdots \mathrm{H} 7$ & 2.060 & 0.540 & O10-H7-N3 & 142.70 & & \\
\hline \multirow[t]{2}{*}{ TUW $_{1}$} & $\mathrm{~S} 1 \cdots \mathrm{H} 9$ & 2.368 & 0.682 & S1-H9-O10 & 148.47 & \multirow[t]{2}{*}{7.28} & \multirow[t]{2}{*}{5.67} \\
\hline & $\mathrm{O} 10 \cdots \mathrm{H} 5$ & 1.940 & 0.660 & O10-H5-N3 & 155.02 & & \\
\hline \multirow[t]{2}{*}{$\mathbf{U W}_{2}$} & O9 $\cdots \mathrm{H} 8$ & 2.240 & 0.355 & O9-H8-N4 & 142.00 & \multirow[t]{2}{*}{5.10} & \multirow[t]{2}{*}{4.68} \\
\hline & 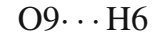 & 2.200 & 0.400 & O9-H6-N4 & 145.78 & & \\
\hline \multirow[t]{2}{*}{$\mathbf{T U W}_{2}$} & O9 $\cdots \mathrm{H} 8$ & 2.164 & 0.436 & O9-H8-N4 & 151.38 & \multirow[t]{2}{*}{6.05} & \multirow[t]{2}{*}{5.35} \\
\hline & 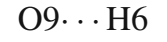 & 2.164 & 0.436 & O9-H6-N4 & 151.38 & & \\
\hline \multirow[t]{2}{*}{$\mathrm{UOW}_{1}$} & $\mathrm{O} 1 \cdots \mathrm{H} 10$ & 1.730 & 0.870 & O1-H10-O11 & 158.01 & \multirow[t]{2}{*}{8.74} & \multirow[t]{2}{*}{8.59} \\
\hline & $\mathrm{O} 1 \cdots \mathrm{H} 8$ & 1.930 & 0.670 & O1-H8-N5 & 111.98 & & \\
\hline \multirow[t]{2}{*}{ TUSW $_{1}$} & $\mathrm{O} 1 \cdots \mathrm{H} 10$ & 1.710 & 0.890 & O1-H12-O10 & 158.13 & 10.54 & 9.29 \\
\hline & $\mathrm{O} 11 \cdots \mathrm{H} 8$ & 1.839 & 0.761 & O10-H8-N5 & 173.24 & & \\
\hline $\mathrm{UOW}_{2}$ & $\mathrm{O} 2 \cdots \mathrm{H} 10$ & 2.200 & 0.400 & $\mathrm{O} 2-\mathrm{H} 10-\mathrm{O} 11$ & 122.95 & 7.09 & 6.67 \\
\hline & $\mathrm{O} 11 \cdots \mathrm{H} 6$ & 1.960 & 0.640 & O11-H6-N4 & 151.40 & & \\
\hline TUSW $_{2}$ & $\mathrm{~S} 2 \cdots \mathrm{H} 10$ & 3.128 & -0.922 & S2-H10-O11 & 100.62 & 7.78 & 4.28 \\
\hline & $\mathrm{O} 11 \cdots \mathrm{H} 6$ & 1.970 & 0.630 & O11-H6-N4 & 167.15 & & \\
\hline $\mathrm{UOW}_{3}$ & $\mathrm{O} 1 \cdots \mathrm{H} 8$ & 1.789 & 0.811 & O1-H8-N5 & 116.49 & 6.60 & 6.50 \\
\hline & $\mathrm{O} 10 \cdots \mathrm{H} 7$ & 2.154 & 0.446 & O10-H7-N4 & 145.71 & & \\
\hline & $\mathrm{O} 10 \cdots \mathrm{H} 9$ & 2.180 & 0.420 & O10-H9-N5 & 142.18 & & \\
\hline TUSW $_{3}$ & $\mathrm{O} 1 \cdots \mathrm{H} 8$ & 2.031 & 0.569 & O1-H8-N5 & 117.40 & 9.11 & 5.58 \\
\hline & $\mathrm{O} 10 \cdots \mathrm{H} 7$ & 2.185 & 0.415 & O10-H7-N4 & 142.40 & & \\
\hline & $\mathrm{O} 10 \cdots \mathrm{H} 9$ & 2.220 & 0.380 & O10-H9-N5 & 137.70 & & \\
\hline
\end{tabular}

Three different conformations $\mathbf{F W}_{\mathbf{1}}, \mathbf{F} \mathbf{W}_{\mathbf{2}}$ and $\mathbf{F} \mathbf{W}_{\mathbf{3}}$ for the formamide-water adduct have been optimized and are shown in figure $1 . \mathbf{F W}_{\mathbf{1}}$ is the most stabilized adduct with oxygen of formamide as the hydrogen bond acceptor and $\mathrm{N}-\mathrm{H}$ as hydrogen bond donor to water. It is perceived that the adduct $\mathbf{F W}_{\mathbf{1}}$ has two hydrogen bonds with lengths $(\mathrm{O} 1 \cdots \mathrm{H} 8)$ and $(\mathrm{O} 7 \cdots \mathrm{H} 6)$ of $1.947 \AA$ and $2.060 \AA$ and angles of $145.30^{\circ}$ and $136.40^{\circ}$ respectively with $\Delta \mathrm{E}_{\text {Corr }}$ of $6.34 \mathrm{kcal} / \mathrm{mol}$. The difference in hydrogen bond distances from the respective sum of van der Waals radii and the $\rho$ values at the $\mathrm{BCP}$ of two hydrogen bonds suggest both the hydrogen bonds play significant role in stabilizing the adduct. Experimental results reported by Langley et al. ${ }^{84}$ include the hydrogen bond distance and angles in the formamidewater adduct in $\mathbf{F W}_{\mathbf{1}}$ conformation as $(\mathrm{O} \cdots \mathrm{H}-\mathrm{O}=$ $1.902 \AA, \angle \mathrm{O}-\mathrm{H}-\mathrm{O}=151.1^{\circ}, \mathrm{O} \cdots \mathrm{H}-\mathrm{N}=2.002 \AA, \angle \mathrm{O}-$ $\mathrm{H}-\mathrm{N}=141.5^{\circ}$ ) which matches with the values obtained at MP2/6-311++ $\mathrm{G}^{* *}$ [L2] levels with small variations. The other two adducts of formamide with water $\mathbf{F} \mathbf{W}_{\mathbf{2}}$ 
and $\mathbf{F W}_{\mathbf{3}}$ are stabilized through single hydrogen bond as reflected by the geometrical parameters in table 1 and AIM analysis (table TS39) and thereby, their stabilization energies are relatively lower. The hydrogen bond distances in $\mathbf{F W}_{\mathbf{2}}$ and $\mathbf{F W}_{\mathbf{3}}$ are $\mathrm{O} 7 \cdots \mathrm{H} 5$ and $\mathrm{O} 1 \cdots \mathrm{H} 7$ are $1.995 \AA$ and $1.900 \AA$ and angles of $177.61^{\circ}$ and $156.63^{\circ}$, respectively with difference of $0.13 \mathrm{kcal} / \mathrm{mol}$ in $\Delta \mathrm{E}_{\text {Corr }}$. The geometrical parameters for the hydrogen bond have an agreement with the experimentally reported values for similar adducts $\mathbf{F W}_{2}(\mathrm{O} \cdots \mathrm{H}-\mathrm{O}=$ $\left.1.981 \AA, \angle \mathrm{O}-\mathrm{H}-\mathrm{O}=173.9^{\circ}\right)$ and $\mathbf{F W}_{3}(\mathrm{O} \cdots \mathrm{H}-\mathrm{O}=$ $\left.1.907 \AA, \angle \mathrm{O}-\mathrm{H}-\mathrm{O}=156.1^{\circ}\right){ }^{84}$

The particulars of three adducts of thioformamide with water listed in table 1 also suggest that the most stabilized structure $\mathbf{T F W}_{\mathbf{1}}$ out of three is analogous to the most stable formamide-water adduct. The adduct TFW $_{\mathbf{1}}$ is stabilized by two hydrogen bonds; $\mathrm{S} 1 \cdots \mathrm{H} 8$ $(2.394 \AA)$ and $\mathrm{O} 7 \cdots \mathrm{H} 6(1.940 \AA)$ with $\Delta \mathrm{E}_{\mathrm{Corr}}$ of $5.23 \mathrm{kcal} / \mathrm{mol}$. The $\mathrm{S}$ and $\mathrm{N}-\mathrm{H}$ of thioformamide act as hydrogen bond acceptor and hydrogen bond donor towards water molecule respectively and the $\Delta \mathrm{E}_{\text {Corr }}$ is $1.11 \mathrm{kcal} / \mathrm{mol}$ lower in comparison to that of $\mathbf{F} \mathbf{W}_{\mathbf{1}}$. The O7... H5 hydrogen bonded adduct $\mathbf{T F} \mathbf{W}_{2}$, has hydrogen bond distance of $1.961 \AA$ and angle of $176.57^{\circ}$. Interestingly both $\mathbf{T F W} \mathbf{2}_{\mathbf{2}}$ and $\mathbf{F W}_{\mathbf{2}}$ involve single hydrogen bond $\mathrm{N}-\mathrm{H} \cdots \mathrm{O}_{\text {water }}$ interactions but the $\Delta \mathrm{E}_{\text {Corr }}$ of stabilization energy of $\mathbf{T F} \mathbf{W}_{\mathbf{2}}$ is relatively higher $(0.31 \mathrm{kcal} / \mathrm{mol})$ supported by shorter hydrogen bond distance. During the MP2 and B3LYP calculations with the same basis set, the maximum stability difference among three conformation of formamide and thioformamide water adduct is for $\mathbf{F} \mathbf{W}_{\mathbf{1}}$ and $\mathbf{T F W} \mathbf{W}_{\mathbf{1}}$ is 0.87 and $1.58 \mathrm{kcal} / \mathrm{mol}$ respectively.

Two conformations have been optimized for the adduct between urea and water in 1:1 ratio. Both $\mathbf{U} \mathbf{W}_{1}$ and $\mathbf{U W}_{2}$ are stabilized by the two hydrogen bonds each. However, $\mathbf{U W}_{\mathbf{1}}$ with oxygen and N-H of urea as hydrogen bond acceptor and donor respectively towards water is $2 \mathrm{kcal} / \mathrm{mol}$ more stable relative to $\mathbf{U W}_{2}$ wherein two N-H bonds of two amino groups act as hydrogen bond donor to oxygen of water. The two hydrogen bond distances in $\mathbf{U W}_{\mathbf{1}}$ are $\mathrm{O} 1 \cdots \mathrm{H} 9$ and $\mathrm{O} 10 \cdots \mathrm{H} 7$ are $1.906 \AA$ and $2.060 \AA$ with angles $149.94^{\circ}$ and $142.70^{\circ}$ respectively. For $\mathbf{U W}_{2}$ adduct, oxygen of water acts as hydrogen bond acceptor to N4-H8 and N3-H6 of urea with the hydrogen bond

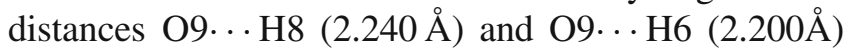
and angles of $142.00^{\circ}$ and $145.78^{\circ}$. The $\mathbf{T U} \mathbf{W}_{\mathbf{1}}$ being analogous to $\mathbf{U W}_{\mathbf{1}}$ has $\Delta \mathrm{E}_{\mathrm{Corr}}$ of $5.67 \mathrm{kcal} / \mathrm{mol}$ while $\mathbf{T U W}_{2}$ has $\Delta \mathrm{E}_{\text {Corr }}$ of $5.35 \mathrm{kcal} / \mathrm{mol}$. The maximum difference for $\Delta \mathrm{E}_{\text {Corr }}$ for both selected theoretical methods for $\mathbf{U} \mathbf{W}_{\mathbf{1}}$ and $\mathbf{T} \mathbf{U} \mathbf{W}_{\mathbf{1}}$ is 0.83 and $1.61 \mathrm{kcal} / \mathrm{mol}$ respectively.
In case of urea monoxide, the attempt to optimize the adduct with hydrogen bonding to $\mathrm{O} 1$ reveals adduct $\mathbf{U O W}_{\mathbf{1}}$, wherein there is intramolecular N5-H8... O1 hydrogen bond along with $\mathrm{O} 1 \cdots \mathrm{H} 10-\mathrm{O} 11$ intermolecular hydrogen bond which exhibits the $\Delta \mathrm{E}_{\text {Corr }}$ of 8.59 $\mathrm{kcal} / \mathrm{mol}$. The hydrogen bond distances in the two hydrogen bonds are $1.730 \AA$ and $1.930 \AA$ respectively with angles of $158.01^{\circ}$ and $111.98^{\circ}$ respectively. The order of stability for most stable adducts of formamide, urea and urea monoxide is $\mathbf{U O W}_{1}>\mathbf{U W}_{1}>\mathbf{F} \mathbf{W}_{1}$. The thio-analog $\mathbf{T U S W}_{\mathbf{1}}$ reflects six-membered cyclic structure with the presence of two intermolecular $\mathrm{O} 1 \cdots \mathrm{H} 10$ and $\mathrm{O} 11 \cdots \mathrm{H} 8$ hydrogen bonds with bond distances $1.710 \AA$ and $1.839 \AA$. Both the bonds are relatively stronger, as suggested by geometrical parameters and $\Delta \mathrm{E}_{\mathrm{Corr}}$. The $\mathbf{T} \mathbf{U S} \mathbf{W}_{\mathbf{1}}$ adduct is $0.70 \mathrm{kcal} / \mathrm{mol}$ more stabilized than $\mathbf{U O W}_{\mathbf{1}}$.

The $\mathrm{O} 2$ and H6-N4 bond of urea monoxide acts as hydrogen acceptor, and hydrogen bond donor respectively toward water in $\mathbf{U} \mathbf{O} \mathbf{W}_{2}$ with hydrogen bond distances of $2.200 \AA$ and $1.960 \AA$ and angles of $122.95^{\circ}$ and $151.40^{\circ}$ respectively. The N4-H6 $\cdots$ O11 hydrogen bond in $\mathbf{T U S W _ { 2 }}$ has a bond distance of $1.970 \AA$ with an angle of $167.15^{\circ}$ and $\Delta \mathrm{E}_{\mathrm{Corr}}$ of $4.28 \mathrm{kcal} / \mathrm{mol}$.

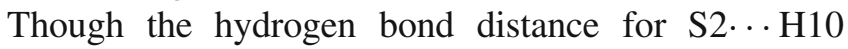
is longer than the sum of van der Waals radii of the two participating atoms, the presence of hydrogen bond is indicated by the BCP (table TS39). Three hydrogen bond interactions are located in the adducts $\mathbf{U O W}_{\mathbf{3}}$ and $\mathbf{T U S} \mathbf{W}_{\mathbf{3}}$ with the bifurcated hydrogen bonding $\mathrm{N}-\mathrm{H} \cdots \mathrm{O} \cdots \mathrm{H}-\mathrm{N}$ interaction in which the water acts as hydrogen bond acceptor and urea monoxide or thiourea monoxide acts as hydrogen bond donor and one intramolecular hydrogen bond. The $\mathbf{U O W}_{\mathbf{3}}$ adduct with bond distance $(\mathrm{O} 1 \cdots \mathrm{H} 8)$ $1.789 \AA,(\mathrm{O} 10 \cdots \mathrm{H} 7) 2.154 \AA$ and $(\mathrm{O} 10 \cdots \mathrm{H} 9) 2.180 \AA$ and angles of $116.49^{\circ}, 145.71^{\circ}$ and $142.18^{\circ}$ respectively has $\Delta \mathrm{E}_{\text {Corr }}$ of $6.50 \mathrm{kcal} / \mathrm{mol}$. TUSW $301 . . \mathrm{H} 8$, $\mathrm{O} 10 \cdots \mathrm{H} 7$ and $\mathrm{O} 10 \cdots \mathrm{H} 9$ are $2.031 \AA, 2.185 \AA$ and $2.220 \AA$ with angles of $117.40^{\circ}, 142.40^{\circ}$ and $137.70^{\circ}$, respectively. The adduct $\mathbf{U} \mathbf{O W} \mathbf{W}_{\mathbf{3}}$ is $0.92 \mathrm{kcal} / \mathrm{mol}$ more stabilized than $\mathbf{T U S W}_{\mathbf{3}}$. The order of stabilization for urea monoxide-water adducts is $\mathbf{U O W}_{1}>\mathbf{U O W}_{\mathbf{2}}>$ $\mathbf{U O W}_{\mathbf{3}}$ whereas for thiourea monoxide-water adduct is TUSW $_{1}>$ TUSW $_{3}>$ TUSW $_{2}$. In the adducts of urea monoxide and their thio-analogs, the B3LYP calculations show a tendency to give a larger value for the $\Delta \mathrm{E}_{\text {Corr }}$ compared to the MP2 values with difference falls in range $0.10-3.5 \mathrm{kcal} / \mathrm{mol}$.

For comparing the hydrogen bond strength and hydrogen bonding ability of the molecules with themselves, the homodimers of the molecules have also been studied. The optimization of homodimers of the 
selected molecules have been carried out at B3LYP/6$311++\mathrm{G}^{* *}$ [L1] and MP2/6-311++G** [L2] theoretical levels. The presence of hydrogen bonds in the homodimers is confirmed through location of BCP with AIM studies (table TS40). The results depict that the stabilization energies for optimized homodimers calculated at MP2/6-311++G** [L2] method are higher than those obtained using B3LYP/6-311++ $\mathrm{G}^{* *}$ [L1] method. The optimization of homodimers of formamide revealed the presence of five minima. Figure 2 shows the minima for formamide homodimer and table 2 summarizes their structural parameters important for hydrogen bonding. The most stable $\mathbf{D F}_{\mathbf{1}}$, which correspond to planar cyclic structure involving two hydrogen bonds $\mathrm{N}-\mathrm{H} \cdots \mathrm{O}=\mathrm{C}$ with hydrogen bond distance $1.890 \AA$ and $1.880 \AA$ and nearly same hydrogen bond angle $172.8^{\circ}$ with $\Delta \mathrm{E}_{\text {Corr }} 12.34 \mathrm{kcal} / \mathrm{mol}$. The planar $\mathbf{D F}_{2}$ comprise of hydrogen bonds $\mathrm{N}$ $\mathrm{H} \cdots \mathrm{O}=\mathrm{C}$ and $\mathrm{C}-\mathrm{H} \cdots \mathrm{O}=\mathrm{C}$ with bonding distance of $2.316 \AA$ and $1.924 \AA$ and angles of $141.23^{\circ}$ and $167.20^{\circ}$ respectively result in relatively lower $\Delta \mathrm{E}_{\mathrm{Corr}}$ value of $8.54 \mathrm{kcal} / \mathrm{mol}$ while the homodimers $\mathbf{D F}_{\mathbf{3}}$ and $\mathbf{D} \mathbf{F}_{\mathbf{4}}$ are non-planar. The presence of single hydrogen bond in $\mathbf{D F}_{\mathbf{4}}$ and the two hydrogen bonds in $\mathbf{D F}_{\mathbf{3}}$ show larger deviation from linearity and the stabilization associated with these homodimers are comparatively lower. The planar homodimer $\mathbf{D F}_{5}$ with $\Delta \mathrm{E}_{\text {Corr }}$ of $5.01 \mathrm{kcal} / \mathrm{mol}$ is stabilized by $\mathrm{O} 1 \cdots \mathrm{H} 9$ and $\mathrm{H} 6 \cdots \mathrm{O} 7$ where the hydrogen bond distances and angles are $(2.389 \AA$ and $2.387 \AA)$ and $\left(138.68^{\circ}\right.$ and $\left.138.75^{\circ}\right)$ respectively. The stability order for formamide dimer is $\mathbf{D F}_{\mathbf{1}}>\mathbf{D F}_{\mathbf{2}}>$ $\mathrm{DF}_{3}>\mathrm{DF}_{4}>\mathrm{DF}_{5}$.

Figure 2 also depicts the structure corresponding to the minima on the potential surface of thioformamide dimers and table 2 lists their structural parameters important for hydrogen bonding. The structures are similar to those of formamide homodimer and follow the same stability sequence. Again, the most stable structure occurs in a conformation $\mathbf{D T F} \mathbf{F}_{\mathbf{1}}$ where the two molecules form two equivalent $\mathrm{N}-\mathrm{H} \cdots \mathrm{S}=\mathrm{C}$ hydrogen bonds that results in $\Delta \mathrm{E}_{\mathrm{Corr}}$ of $10.50 \mathrm{kcal} / \mathrm{mol}$ with each bond distance $2.382 \AA$ and angle $171.0^{\circ}$ nearly same. $\mathbf{D T F}_{2}$ forms two hydrogen bonds $\mathrm{N}-\mathrm{H} \cdots \mathrm{S}=\mathrm{C}$ and $\mathrm{C}-\mathrm{H} \cdots \mathrm{S}=\mathrm{C}$ with $\Delta \mathrm{E}_{\mathrm{Corr}}$ of $8.35 \mathrm{kcal} / \mathrm{mol}$ defined by the hydrogen bond distance H4 . S S 7 of $2.400 \AA$ and angle $159.66^{\circ}$ in the former bond. The position of $\mathrm{S} 1$ and $\mathrm{H} 9$ does not fall within their sum of van der Waals radii with angle of $106.35^{\circ}$, but the presence of the BCP (table TS40) reflects presence of electrostatic interactions between the two atoms. The homodimer $\mathbf{D T F}_{\mathbf{3}}$ and $\mathbf{D T F}_{\mathbf{4}}$ are stabilized with $\Delta \mathrm{E}_{\text {Corr }}$ of 6.25 and $5.63 \mathrm{kcal} / \mathrm{mol}$ respectively. The hydrogen bond distances in $\mathbf{D T F}_{3}, \mathrm{H} 5 \cdot . \mathrm{S} 7$ and N3 $\cdots \mathrm{H} 12$ are $2.492 \AA$ and
$2.319 \AA$ with angles of $148.06^{\circ}$ and $146.54^{\circ}$ respectively. Whereas $\mathbf{D T F}_{4}$ is stabilized with single hydrogen bond with bond distance $2.449 \AA$ and angle $151.24^{\circ}$. $\mathbf{D T F}_{5}$ and $\mathbf{D F}_{5}$ have symmetrically hydrogen bonded cyclic structure involving $\mathrm{S} \cdots \mathrm{H}-\mathrm{C}$ in the former and $\mathrm{O} \cdots \mathrm{H}-\mathrm{C}$ hydrogen bonds in the latter but the former dimer is $0.23 \mathrm{kcal} / \mathrm{mol}$ more stabilized. The formamide homodimers are more stabilized than thioformamide with two exceptions $\left(\mathbf{D F}_{\mathbf{3}}, \mathbf{D} \mathbf{T F}_{\mathbf{3}}\right)$ and $\left(\mathbf{D F}_{\mathbf{5}}, \mathbf{D} \mathbf{T F}_{\mathbf{5}}\right)$. The homodimers of formamide and thioformamide are more stable than their monohydrated adducts respectively. The most stable $\mathbf{D F}_{\mathbf{1}}$ is $6.0 \mathrm{kcal} / \mathrm{mol} \mathrm{more} \mathrm{sta-}$ bilized as compared to $\mathbf{F W}_{\mathbf{1}}$ adduct whereas formation of $\mathbf{D T F}_{1}$ is $5.27 \mathrm{kcal} / \mathrm{mol}$ more strengthened in contrast to $\mathbf{T F W}_{\mathbf{1}}$. In the homodimers of formamide and their thio-analogs, the B3LYP calculations often produce a lower value for the $\Delta \mathrm{E}_{\mathrm{Corr}}$ on comparing to the MP2 values.

Two conformations for the energy minimum structure have been obtained in case of urea homodimer, and these structures are reported in figure 2. These structures adorn two hydrogen bonds each. In $\mathbf{D U}_{1}$, one of the N-H of each monomer unit acts as hydrogen bond donor towards the carbonyl oxygen as hydrogen bond acceptor. The distances and angles of each hydrogen bonds $\mathrm{O} 1 \cdots \mathrm{H} 15$ and H5 . O 9 are $1.864 \AA$ and angles $176.22^{\circ}$ nearly same. The $\mathbf{D U}_{2}$ dimer involves two $\mathrm{N}-\mathrm{H} \cdots \mathrm{O}=\mathrm{C}$ and $\mathrm{N}-\mathrm{H} \cdots \mathrm{N}-\mathrm{C}$ hydrogen bonds with distances $1.994 \AA$ and $2.129 \AA$ and angles $150.97^{\circ}$ and $155.24^{\circ}$ respectively. The differences in $\Delta \mathrm{E}_{\mathrm{Corr}}$ of homodimers $\mathbf{D} \mathbf{U}_{1}$ and $\mathbf{D} \mathbf{U}_{2}$ is $2.06 \mathrm{kcal} / \mathrm{mol}$ with the stability order $\mathbf{D U}_{\mathbf{1}}>\mathbf{D U}_{\mathbf{2}}$. The homodimers of thiourea labeled as $\mathbf{D T U} \mathbf{T}_{1}$ and $\mathbf{D T U} \mathbf{Z}_{2}$ that have conformation orientation similar to $\mathbf{D U}_{\mathbf{1}}$ and $\mathbf{D} \mathbf{U}_{2}$ respectively are also placed in figure 2 . The $\mathbf{D T U} \mathbf{T}_{\mathbf{1}}$ has two equivalent hydrogen bonds $(\mathrm{N}-\mathrm{H} \cdots \mathrm{S})$ with hydrogen bond distance and angle of $2.365 \AA$ and $169.26^{\circ}$ respectively nearly same. However, the $\mathbf{D T U}_{\mathbf{1}}$ is $0.59 \mathrm{kcal} / \mathrm{mol}$ more stabilized than the $\mathbf{D U}_{\mathbf{1}}$. The $\mathbf{D U}_{\mathbf{1}}$ is $4.72 \mathrm{kcal} / \mathrm{mol}$ more stabilized as compared to $\mathbf{U W}_{1}$ whereas $\mathbf{D T U}_{1}$ is $5.81 \mathrm{kcal} / \mathrm{mol}$ more stabilized as compared to $\mathbf{T U} \mathbf{W}_{\mathbf{1}}$ adduct.

The DUO ${ }_{1}$ with single $\mathrm{N}-\mathrm{H}$.. O bond distance and angle of $1.889 \AA$ and $169.56^{\circ}$ stabilized by $\Delta \mathrm{E}_{\text {Corr }}$ of $11.05 \mathrm{kcal} / \mathrm{mol}$. Similar conformation of homodimer DTUS $_{1}$ is obtained for thiourea monoxide with $\Delta \mathrm{E}_{\text {Corr }}$ of $10.25 \mathrm{kcal} / \mathrm{mol}$ with hydrogen bond distance of $1.933 \AA$ and angle of $150.05^{\circ}$. The stability order is as follows $\mathbf{D U O}_{1}>\mathbf{D T U S}_{\mathbf{1}}$. It is found that stability difference for homodimer of urea monoxide and thiourea monoxide is about $2.55-2.75 \mathrm{kcal} / \mathrm{mol}$ for two selected methods. The $\mathbf{D U} \mathbf{O}_{1}$ is $2.46 \mathrm{kcal} / \mathrm{mol}$ more stabilized as compared to most stable $\mathbf{U O W}_{\mathbf{1}}$ adduct while other 


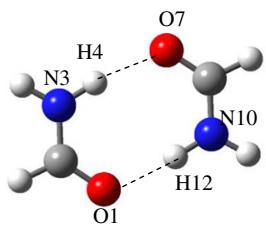

$\mathrm{DF}_{1}$

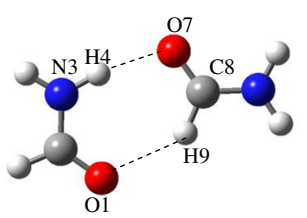

$\mathrm{DF}_{2}$

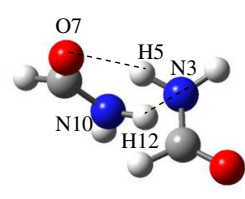

$\mathrm{DF}_{3}$

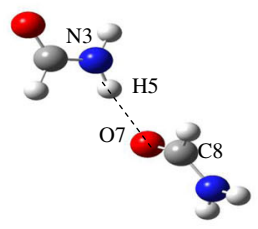

$\mathrm{DF}_{4}$

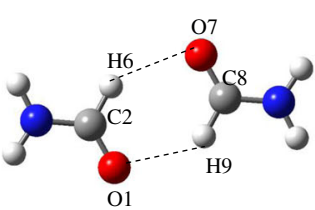

$\mathrm{DF}_{5}$

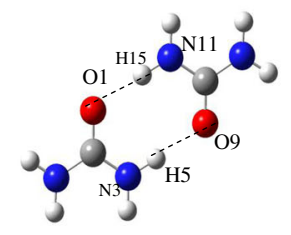

$\mathrm{DU}_{1}$

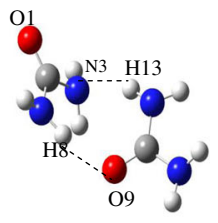

$\mathrm{DU}_{2}$

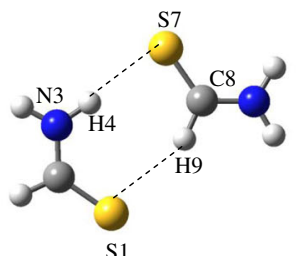

DTF $_{2}$

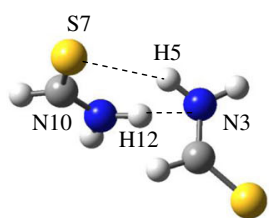

$\mathrm{DTF}_{3}$

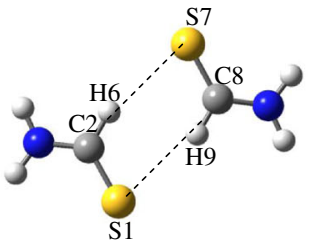

$\mathrm{DTF}_{4}$

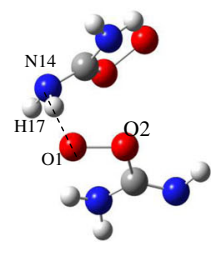

DUO $_{1}$
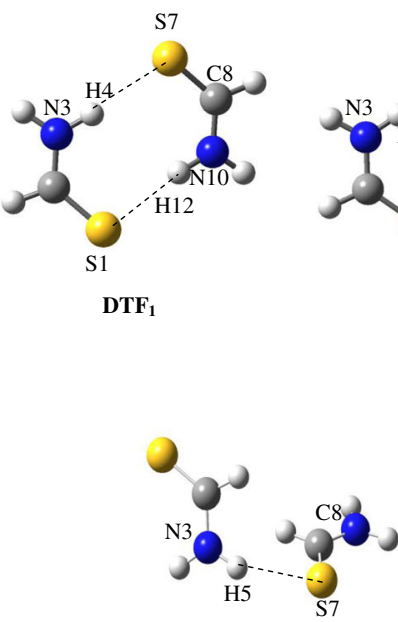

DTF $_{5}$

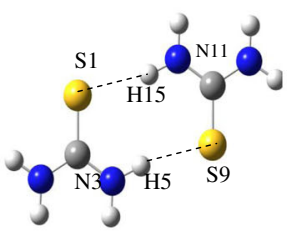

DTU $_{1}$

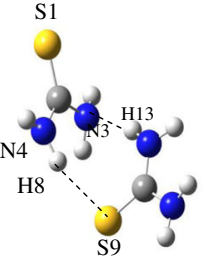

DTU $_{2}$

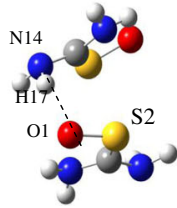

DTUS $_{1}$

Figure 2. The optimized hydrogen bonded homodimers of selected molecules at MP2/6-311++G** [L2] level. 
Table 2. Hydrogen bond distances (r) in $(\AA)$, angles in $\left(^{\circ}\right)$ important for hydrogen bonding interactions, difference of hydrogen bond distances from sum of vander Waals radii $(\Delta \mathrm{r})$ at MP2/6-311++ $\mathrm{G}^{* *}[\mathbf{L 2}]$ level and stabilization energies $\left(\Delta \mathrm{E}_{\mathrm{Corr}}\right)$ in $(\mathrm{kcal} / \mathrm{mol})$ for homodimers under investigation at B3LYP/6-311++G** [L1] and MP2/6-311++G** [L2] levels are obtained.

\begin{tabular}{|c|c|c|c|c|c|c|c|}
\hline \multirow{3}{*}{$\begin{array}{l}\text { Homodimers } \\
\mathbf{D F}_{1}\end{array}$} & \multirow{2}{*}{\multicolumn{2}{|c|}{$\begin{array}{l}\text { Hydrogen bond } \\
\text { distances(r) }\end{array}$}} & \multirow{3}{*}{$\begin{array}{c}\Delta \mathrm{r}=\mathrm{r}_{\mathrm{VW} *^{-}} \mathrm{r} \\
0.710 \\
0.720\end{array}$} & \multirow{2}{*}{\multicolumn{2}{|c|}{$\begin{array}{l}\text { Hydrogen bonding } \\
\text { angles }\end{array}$}} & \multicolumn{2}{|c|}{$\Delta \mathrm{E}_{\text {Corr }}$} \\
\hline & & & & & & \multirow{2}{*}{$\begin{array}{c}\mathbf{L 1} \\
12.05\end{array}$} & \multirow{2}{*}{$\begin{array}{c}\frac{\mathbf{L 2}}{12.34} \\
\end{array}$} \\
\hline & $\begin{array}{l}\mathrm{O} 1 \cdots \mathrm{H} 12 \\
\mathrm{H} 4 \cdots \mathrm{O} 7\end{array}$ & $\begin{array}{l}1.890 \\
1.880\end{array}$ & & $\begin{array}{l}\text { O1-H12-N10 } \\
\text { N3-H4-O7 }\end{array}$ & $\begin{array}{l}172.80 \\
172.85\end{array}$ & & \\
\hline DTF $_{1}$ & $\begin{array}{l}\mathrm{S} 1 \cdots \mathrm{H} 12 \\
\mathrm{H} 4 \cdots \mathrm{S} 7\end{array}$ & $\begin{array}{l}2.382 \\
2.382\end{array}$ & $\begin{array}{l}0.668 \\
0.668\end{array}$ & $\begin{array}{l}\text { S1-H12-N10 } \\
\text { N3-H4-S7 }\end{array}$ & $\begin{array}{l}171.35 \\
171.40\end{array}$ & 10.09 & 10.50 \\
\hline $\mathrm{DF}_{2}$ & $\begin{array}{l}\mathrm{O} 1 \cdots \mathrm{H} 9 \\
\mathrm{H} 4 \cdots \mathrm{O} 7\end{array}$ & $\begin{array}{l}2.316 \\
1.924\end{array}$ & $\begin{array}{l}0.284 \\
0.676\end{array}$ & $\begin{array}{l}\text { O1-H9-C8 } \\
\text { N3-H5-O7 }\end{array}$ & $\begin{array}{l}141.23 \\
167.20\end{array}$ & 8.22 & 8.54 \\
\hline $\mathrm{DTF}_{2}$ & $\begin{array}{l}\text { S1 } \cdots \text { H9 } \\
\text { H4 } \cdots \text { S7 }\end{array}$ & $\begin{array}{l}3.953 \\
2.400\end{array}$ & $\begin{array}{c}-0.903 \\
0.650\end{array}$ & $\begin{array}{l}\text { S1-H9-C8 } \\
\text { N3-H5-S7 }\end{array}$ & $\begin{array}{l}106.35 \\
159.66\end{array}$ & 8.11 & 8.35 \\
\hline $\mathrm{DF}_{3}$ & $\begin{array}{c}\mathrm{H} 5 \cdots \mathrm{O} 7 \\
\mathrm{~N} 3 \cdots \mathrm{H} 12\end{array}$ & $\begin{array}{l}2.025 \\
2.416\end{array}$ & $\begin{array}{l}0.575 \\
0.324\end{array}$ & $\begin{array}{c}\text { O7-H5-N3 } \\
\text { N3-H12-H11 }\end{array}$ & $\begin{array}{l}154.12 \\
116.58\end{array}$ & 5.80 & 6.01 \\
\hline $\mathrm{DTF}_{3}$ & $\begin{array}{c}\mathrm{H} 5 \cdots \mathrm{S} 7 \\
\mathrm{~N} 3 \cdots \mathrm{H} 12\end{array}$ & $\begin{array}{l}2.492 \\
2.319\end{array}$ & $\begin{array}{l}0.558 \\
0.731\end{array}$ & $\begin{array}{l}\text { O7-H5-N3 } \\
\text { N3-H12-N10 }\end{array}$ & $\begin{array}{l}148.06 \\
146.54\end{array}$ & 6.05 & 6.25 \\
\hline $\mathrm{DF}_{4}$ & $\mathrm{H} 5 \cdots \mathrm{O} 7$ & 1.976 & 0.624 & N3-H5-O7 & 166.50 & 5.46 & 5.80 \\
\hline $\mathrm{DTF}_{4}$ & $\mathrm{H} 5 \cdots \mathrm{S} 7$ & 2.449 & 0.601 & N3-H5-S7 & 151.24 & 5.30 & 5.63 \\
\hline $\mathrm{DF}_{5}$ & $\begin{array}{l}\mathrm{O} 1 \cdots \mathrm{H} 9 \\
\mathrm{H} 6 \cdots \mathrm{O} 7\end{array}$ & $\begin{array}{l}2.389 \\
2.387\end{array}$ & $\begin{array}{l}0.211 \\
0.213\end{array}$ & $\begin{array}{l}\text { O1-H9-C8 } \\
\text { C2-H6-O7 }\end{array}$ & $\begin{array}{l}138.68 \\
138.75\end{array}$ & 4.50 & 5.01 \\
\hline DTF $_{5}$ & 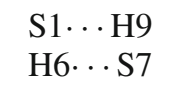 & $\begin{array}{l}2.724 \\
2.723\end{array}$ & $\begin{array}{l}0.326 \\
0.327\end{array}$ & $\begin{array}{l}\text { S1-H9-C8 } \\
\text { C2-H6-S7 }\end{array}$ & $\begin{array}{l}159.50 \\
159.36\end{array}$ & 4.66 & 5.24 \\
\hline $\mathrm{DU}_{1}$ & $\begin{array}{l}\mathrm{O} 1 \cdots \mathrm{H} 15 \\
\mathrm{H} 5 \cdots \mathrm{O} 9\end{array}$ & $\begin{array}{l}1.864 \\
1.864\end{array}$ & $\begin{array}{l}0.736 \\
0.736\end{array}$ & $\begin{array}{l}\text { O1-H15-N11 } \\
\text { O9-H5-N3 }\end{array}$ & $\begin{array}{l}176.22 \\
176.20\end{array}$ & 10.34 & 10.89 \\
\hline DTU $_{1}$ & $\begin{array}{l}\mathrm{S} 1 \cdots \mathrm{H} 15 \\
\mathrm{H} 5 \cdots \mathrm{S} 9\end{array}$ & $\begin{array}{l}2.365 \\
2.366\end{array}$ & $\begin{array}{l}0.685 \\
0.684\end{array}$ & $\begin{array}{l}\text { S1-H15-N11 } \\
\text { S9-H5-N3 }\end{array}$ & $\begin{array}{l}169.26 \\
169.49\end{array}$ & 8.45 & 11.48 \\
\hline $\mathbf{D U}_{2}$ & $\begin{array}{c}\mathrm{H} 8 \cdots \mathrm{O} 9 \\
\mathrm{~N} 3 \cdots \mathrm{H} 13\end{array}$ & $\begin{array}{l}1.994 \\
2.129\end{array}$ & $\begin{array}{l}0.606 \\
0.611\end{array}$ & $\begin{array}{l}\text { O9-H8-N4 } \\
\text { N3-H13-N10 }\end{array}$ & $\begin{array}{l}150.97 \\
155.24\end{array}$ & 8.11 & 8.83 \\
\hline DTU $_{2}$ & $\begin{array}{c}\mathrm{H} 8 \cdots \mathrm{S} 9 \\
\mathrm{~N} 3 \cdots \mathrm{H} 13\end{array}$ & $\begin{array}{l}2.411 \\
2.047\end{array}$ & $\begin{array}{l}0.639 \\
1.453\end{array}$ & $\begin{array}{l}\text { S9-H8-N4 } \\
\text { N3-H13-N10 }\end{array}$ & $\begin{array}{l}161.76 \\
162.41\end{array}$ & 8.12 & 9.08 \\
\hline DUO $_{1}$ & $\mathrm{O} 1 \cdots \mathrm{H} 17$ & 1.889 & 0.711 & O1-H17-N14 & 169.56 & 8.50 & 11.05 \\
\hline DTUS $_{1}$ & $\mathrm{O} 1 \cdots \mathrm{H} 17$ & 1.933 & 0.667 & O1-H17-N14 & 150.05 & 7.50 & 10.25 \\
\hline
\end{tabular}

adducts, $\mathbf{U} \mathbf{O W}$ and $\mathbf{U O W} \mathbf{W}_{\mathbf{3}}$ are $4.38-4.55 \mathrm{kcal} / \mathrm{mol}$ less stabilized. The DTUS $_{1}$ is $0.96 \mathrm{kcal} / \mathrm{mol}$ more stabilized as compared to most stable $\mathbf{T U S W}_{\mathbf{1}}$ adduct while other adducts, $\mathbf{T} \mathbf{U S} \mathbf{W}_{\mathbf{2}}$ and $\mathbf{T} \mathbf{U S} \mathbf{W}_{\mathbf{3}}$ are $4.67-5.97 \mathrm{kcal} / \mathrm{mol}$ less stabilized.

\subsection{NEDA analysis}

To better understand the nature and relative stability arising from components contributing to the intermolecular attraction in these monohydrated adducts, individual energy components \{ static polarization (ES), induced polarization (PL), self energy correction at each polarizing centre (SE)\}, collectively referred as electrical components (EL) were obtained using NEDA procedures, where EL $=\mathrm{ES}+\mathrm{PL}+\mathrm{SE}$. The EL component describes both static and induced interactions between monomer charge densities, generally compared favourably with estimates from classical point multipole/polarizability approximations. The charge transfer (CT) component describes delocalizing, donoracceptor interactions. CORE accounts for the quantum mechanical effects (Pauli repulsions and exchange) of filled orbital $(\sigma-\sigma)$ interactions that arise from the required antisymmetry of the wave function for the interacting monomers. ${ }^{85}$ The evaluated components at 
B3LYP/6-311++G** [L1] theoretical level are listed in table 3.

As can be seen from table 3, the ES components of most of the adducts are higher than CT component with the exception of four monohydrated adducts $\mathbf{T F W} \mathbf{W}_{\mathbf{1}}$, $\mathbf{T U W}_{1}, \mathbf{U O W}_{1}$ and $\mathbf{T U S W} \mathbf{W}_{1}$. The adduct $\mathbf{T} \mathbf{S} \mathbf{W}_{1}$ shows a difference of $5.57 \mathrm{kcal} / \mathrm{mol}$ between ES and CT while in other three cases the difference is less than $1.22 \mathrm{kcal} / \mathrm{mol}$. The highest ES component is observed for TUSW $_{1}$ amongst all the adducts under study. The adduct $\mathbf{F W}_{\mathbf{1}}$, the most stable of formamide-water adducts has highest ES component amongst the three, while in case of its thio-analogs $\mathbf{T F W}$, though the ES is relatively highest amongst the three conformation, CT component is larger than ES. Results in table reflect that in addition to attractive interactions, EL and CT add significantly to stability and CORE component. This plays an important role in overall stabilization energy. The CT component is more favourable in $\mathbf{T F W}_{\mathbf{1}}$, but high CORE component makes it overall less stabilized in comparison to $\mathbf{F W}_{\mathbf{1}}$. The ES component for $\mathbf{F W}_{\mathbf{1}}$ is $27.3 \%$ of total attractive interactions. In spite of low polarity of C-S bond in $\mathbf{T F W}_{\mathbf{1}}$, in comparison to $\mathrm{C}-\mathrm{O}$ bond in $\mathbf{F W}_{\mathbf{1}}$, the comparable ES component in the two cases indicates favourable placement of other dipoles. The lowest ES component is indicated for the adduct $\mathbf{F} \mathbf{W}_{\mathbf{2}}$. Though both $\mathbf{F} \mathbf{W}_{\mathbf{2}}$ and TFW $_{2}$ have N3-H5 $\cdots$ O 7 hydrogen bond, the hydrogen bond angles and the atomic charges on the hydrogen bond donor and acceptor in the two cases also show negligible difference, the higher ES associated with $\mathbf{T F W}_{2}$ relative to $\mathbf{F W}_{2}$ results from closer proximity of hydrogen bond donor and acceptor in case of $\mathbf{T F W}$. It is interesting to note that in spite of low magnitude of atomic charge on S, the EL component in case of thio-analogs is comparable to that observed for oxocarbonyl compounds with the exception of two adducts.

The EL and CT component explains higher stability of $\mathbf{U W}_{\mathbf{1}}$ and $\mathbf{T U W} \mathbf{W}_{1}$ as compared to $\mathbf{F W} \mathbf{W}_{\mathbf{1}}$ and $\mathbf{T F W} \mathbf{W}_{\mathbf{1}}$ respectively. In fact, in case of $\mathbf{U O W}_{\mathbf{1}}$ and $\mathbf{T U S W _ { 1 }}$ pair, the ES component is higher in the latter and the huge difference can be traced to the presence of highly electronegative oxygen in thiourea monoxide. In case of $\mathbf{T U S W}_{\mathbf{1}}, \mathbf{S}$ does not act as hydrogen bond acceptor but favours in the electron delocalization through polarization of S-O bond as well comparatively larger CT component. In spite of the higher polarizability of sulfur relative to oxygen, the PL component is higher in oxygen adducts $\left(\mathbf{F} \mathbf{W}_{\mathbf{1}}, \mathbf{F} \mathbf{W}_{\mathbf{3}}, \mathbf{U} \mathbf{W}_{\mathbf{1}}, \mathbf{U} \mathbf{O} \mathbf{W}_{\mathbf{2}}\right.$ and $\left.\mathbf{U} \mathbf{O} \mathbf{W}_{\mathbf{3}}\right)$ and the high electronegative nature of oxygen enhances EL component in these adducts relative to the adducts of sulfur. The order of stability for most stable adducts of formamide, urea and urea monoxide is $\mathbf{U O W}_{\mathbf{1}}>$ $\mathbf{U W}_{1}>\mathbf{F W}_{\mathbf{1}}$ is supported by CT and EL from NEDA analysis.

\subsection{Atomic charge analysis}

The atomic charges are reflective of the electrostatic component. The values of atomic charges of hydrogen

Table 3. NEDA Analyses ${ }^{\mathrm{a}}$ of Electrical (EL) \{Static (ES) and Induced Polarization (PL) \}, Charge Transfer (CT), and Core repulsions (CORE) components in the monohydrated adducts under investigation at B3LYP/6-311++ $\mathrm{G}^{* *}$ [L1] level. All the energy components are in $\mathrm{kcal} / \mathrm{mol}$.

\begin{tabular}{lcccccr}
\hline Adducts & ES & PL & EL $^{\mathrm{b}}$ & CT & CORE & $\Delta \mathrm{E}_{\mathrm{INT}}^{\mathrm{c}}$ \\
\hline FW $_{\mathbf{1}}$ & -17.38 & -9.32 & -21.97 & -14.86 & 29.03 & -7.79 \\
TFW $_{\mathbf{1}}$ & -18.49 & -4.99 & -20.99 & -19.01 & 33.41 & -6.58 \\
$\mathbf{F W}_{\mathbf{2}}$ & -8.43 & -4.70 & -10.75 & -7.97 & 14.06 & -4.66 \\
TFW $_{\mathbf{2}}$ & -9.53 & -4.98 & -11.97 & -9.02 & 15.54 & -5.44 \\
$\mathbf{F W}_{\mathbf{3}}$ & -11.36 & -4.89 & -13.80 & -10.06 & 18.13 & -5.72 \\
TFW $_{\mathbf{3}}$ & -9.55 & -3.74 & -11.43 & -8.54 & 15.69 & -4.29 \\
$\mathbf{U W}_{\mathbf{1}}$ & -18.75 & -8.13 & -22.78 & -16.2 & 31.08 & -7.91 \\
TUW $_{\mathbf{1}}$ & -19.22 & -4.38 & -21.44 & -20.44 & 35.07 & -6.82 \\
UW $_{\mathbf{2}}$ & -9.96 & -6.00 & -12.91 & -6.70 & 14.01 & -5.59 \\
TUW $_{\mathbf{2}}$ & -11.70 & -6.74 & -14.99 & -8.22 & 16.36 & -6.85 \\
UOW $_{\mathbf{1}}$ & -19.45 & -4.37 & -21.69 & -19.84 & 32.34 & -9.19 \\
TUSW $_{\mathbf{1}}$ & -30.56 & -11.06 & -35.92 & -36.13 & 58.57 & -13.48 \\
UOW $_{\mathbf{2}}$ & -15.95 & -8.48 & -20.13 & -12.32 & 24.23 & -8.23 \\
TUSW $_{\mathbf{2}}$ & -12.44 & -6.26 & -15.52 & -10.91 & 20.23 & -6.20 \\
UOW $_{\mathbf{3}}$ & -12.68 & -6.74 & -15.98 & -7.62 & 15.79 & -7.81 \\
TUSW $_{\mathbf{3}}$ & -12.28 & -6.28 & -15.36 & -6.80 & 15.72 & -7.44 \\
\hline
\end{tabular}

In NEDA scheme ${ }^{\mathrm{b}} \mathrm{EL}=\mathrm{ES}+\mathrm{PL}+\mathrm{SE},{ }^{\mathrm{c}} \Delta \mathrm{E}_{\mathrm{INT}}=\mathrm{EL}+\mathrm{CORE}+\mathrm{CT}$ 
bond acceptor and hydrogen bond donor are analyzed from NBO obtained at B3LYP/6-311++G** [L1] theoretical level. The atomic charges for all the sixteen monohydrated adduct with water are reported in tables TS41-TS42. Atomic charge analysis indicates that the charge on $\mathrm{S} 1$ is comparatively much smaller in magnitude than on $\mathrm{O} 1$ in the adducts of thioformamide and formamide respectively. Hence, the contribution of electrostatic interactions in adducts involving sulfur of thioformamide as hydrogen bond acceptor is expected to be smaller in comparison to oxygen of formamide. In monohydrated adducts, the oxygen of water is more electron dense than the oxygen of formamide but polarity of $\mathrm{O}-\mathrm{H}$ of water favours the carbonyl oxygen to act as hydrogen bond acceptor.

The decrease in electron density on hydrogen atom of water involved in hydrogen bonding has been accepted as one of the criteria for hydrogen bond and clearly shows that the hydrogen nuclei are deshielded upon hydrogen bond formation. The analysis of atomic charges on atoms involved in hydrogen bond formation in table TS41-TS42 reflects that the hydrogen atoms of the hydrogen bond donors have charge in the range $0.203-0.509$ au. In addition, the charge density on the atom acting as hydrogen bond acceptor is increased. The NEDA study indicated that ES components of thioanalogs of formamide, urea and urea monoxide have comparative value with few exceptions.

Nearly all the atoms in the urea and thiourea undergo variation in atomic charge density upon adduct formation with water in $\mathbf{U} \mathbf{W}_{\mathbf{1}}$ and $\mathbf{T} \mathbf{U} \mathbf{W}_{\mathbf{1}}$ orientations. Relatively high variation in atomic charge on atoms $\mathrm{H} 5, \mathrm{H} 6$ and $\mathrm{H} 8$ is observed. The most stable adduct of urea monoxide with water $\mathbf{U O W}_{\mathbf{1}}$, reflects large atomic charge variations on $\mathrm{O} 1, \mathrm{C} 3$ and both the $\mathrm{N}$ atoms. The addition of water molecule to thiourea monoxide increases charge on $\mathrm{C}$ atom and decreases that on $\mathrm{S}$ atom, which indicates that with the addition of water molecule, the polarity of C-S bond becomes larger. These results are supported by the molecular electrostatic potential (MEP maps) calculated using Molekel 4.3 version on molecules and their adducts with water under study at B3LYP/6-311++ $\mathrm{G}^{* *}$ [L1] theoretical level shown in figure $\mathrm{S} 1$. The red region indicates the most negative potential $\mathrm{V}_{\text {min }}$ while blue region indicates the positive potential $\mathrm{V}_{\max }$. As can be seen from the figure, sulfur and oxygen involved in adducts under study exhibits negative electrostatic potential and hydrogen exhibits positive electrostatic potential. The electrostatic potential on oxygen is $62.75 \mathrm{kcal} / \mathrm{mol}$ while for sulfur is $53.33 \mathrm{kcal} / \mathrm{mol}$ reflects higher stability of adducts of formamide with water relative to thioformamide adducts.
The atomic charges for all the sixteen homodimers are reported in tables TS43-TS45. Atomic charge analysis indicates that the charge on $\mathrm{S} 1$ is relatively -0.427 to -0.515 au lower in magnitude than on $\mathrm{O} 1 \mathrm{in}$ homodimers of thioformamide and formamide respectively. This shows large electrostatic contribution to the total energy in formamide homodimers under study, which dominates over all other stabilizing interactions. However, in case of formamide and thioformamide homodimers, the small difference in stabilization energies is indicated in the results. Polarizations of all the bonds are increased in $\mathbf{D F}_{\mathbf{1}}$ and $\mathbf{D T F}_{\mathbf{1}}$. However, variations in $\mathbf{D F}_{\mathbf{1}}$ are larger at the hydrogen bond acceptor and hydrogen bond donor group. Atomic charge variations in $\mathbf{D U}_{\mathbf{1}}$ also suggest change in polarization of bonds on dimer formation. However, high atomic charge values caused by the presence of the two $-\mathrm{NH}_{2}$ group, the electrostatic interactions are anticipated to be higher in $\mathbf{D} \mathbf{U}_{1}$ relative to $\mathbf{D F} \mathbf{F}_{\mathbf{1}}$. The thio-analogs of urea, also reflects change in bond polarities upon dimer formation. However, the variations are relatively smaller in comparison to $\mathbf{D} \mathbf{U}_{\mathbf{1}}$ formation.

\subsection{NBO analysis}

The second order interactions energies $\left(\mathrm{E}^{(2)}\right)$ of relevant orbital interactions associated with hydrogen bond donor and acceptor from NBO analysis obtained at B3LYP/6-311++G** [L1] theoretical level are reflective of the charge transfer between the monomeric units in monohydrated adducts and are recorded in table 4. The occupancies of the acceptor orbitals are indicative of extent of charge transfer and are also included in the table 4. As can be seen in case of $\mathbf{F} \mathbf{W}_{\mathbf{1}}$, the orbital interactions $\mathrm{n}_{\mathrm{O} 1} \rightarrow \sigma^{*}{ }_{\mathrm{H} 8-\mathrm{O} 7}$ and $\mathrm{n}_{\mathrm{Ow}} \rightarrow \sigma^{*}{ }_{\mathrm{N}-\mathrm{H}}$ stabilize the adduct with $\mathrm{E}^{(2)}$ values of 6.91 and 3.58 $\mathrm{kcal} / \mathrm{mol}$. The $\mathrm{E}^{(2)}$ values also suggest that former interactions are larger in comparison to latter. Hence, strength of $\mathrm{O} 1 \cdots \mathrm{H} 8-\mathrm{O} 7$ is relatively stronger, which is also reflected by the $\rho$ value of the BCP and the hydrogen bond length. The hydrogen bonded $\mathbf{F W}_{\mathbf{2}}$ and $\mathbf{F W}_{3}$ have $\mathrm{n}_{\mathrm{O} 7} \rightarrow \sigma^{*}{ }_{\mathrm{N} 3-\mathrm{H} 5}$ and $\mathrm{n}_{\mathrm{O} 1} \rightarrow \sigma^{*}{ }_{\mathrm{O} 8-\mathrm{H} 7}$ with $\mathrm{E}^{(2)}$ values 6.65 and $7.43 \mathrm{kcal} / \mathrm{mol}$. The $\mathrm{E}^{(2)}$ values for both the hydrogen bonds in $\mathbf{T F W}_{\mathbf{1}}$ are higher in comparison to the respective values present in $\mathbf{F W}_{\mathbf{1}}$ which suggests $\mathrm{CT}$ component to be relatively higher which indeed is reflected in NEDA analysis as well.

The CT in case of $\mathbf{U W}_{\mathbf{1}}$ is indicated to be higher in relation to that in $\mathbf{F} \mathbf{W}_{\mathbf{1}}$ by the $\mathrm{E}^{(2)}$ values. The NEDA also suggests similar results where EL and CT components favour $\mathbf{U W}_{\mathbf{1}}$. The orbital interactions $\mathrm{n}_{\mathrm{O} 1} \rightarrow \sigma^{*}{ }_{\mathrm{H} 10-\mathrm{O} 11}$ with $\mathrm{E}^{(2)}$ value of $17.85 \mathrm{kcal} / \mathrm{mol}$ strengthen the $\mathrm{O} 1 \cdots \mathrm{H} 10$ bond in $\mathbf{U O W}_{1}$ while $\mathrm{n}_{\mathrm{O} 1} \rightarrow$ 
Table 4. Important second order stabilization energies $E^{(2)}(\mathrm{kcal} / \mathrm{mol})$ and occupancies of acceptor orbitals for the orbital interactions strengthening adduct with water at B3LYP/6-311++G** [L1] level.

\begin{tabular}{|c|c|c|c|c|c|c|c|c|c|c|}
\hline \multirow[b]{2}{*}{ Adducts } & \multirow{2}{*}{$\begin{array}{c}\text { D } \\
\text { Molecule }\end{array}$} & \multirow{2}{*}{$\begin{array}{c}\mathrm{A} \\
\mathrm{H}_{2} \mathrm{O}\end{array}$} & \multirow[b]{2}{*}{$\mathrm{E}^{(2)}$} & \multirow{2}{*}{$\begin{array}{c}\mathrm{D} \\
\mathrm{H}_{2} \mathrm{O}\end{array}$} & \multirow{2}{*}{$\begin{array}{c}\text { A } \\
\text { Molecule }\end{array}$} & \multirow[b]{2}{*}{$\mathrm{E}^{(2)}$} & \multicolumn{4}{|c|}{ Occupancies } \\
\hline & & & & & & & Acceptor & $\mathrm{H}_{2} \mathrm{O}$ & Acceptor & Molecule \\
\hline $\mathbf{F W}_{1}$ & $\mathrm{n}_{\mathrm{O} 1} \rightarrow$ & H8-O7 & 6.91 & $\mathrm{n}_{\mathrm{O} 7}$ & $\rightarrow \sigma^{*} \mathrm{~N} 3-\mathrm{H} 6$ & 3.58 & $\sigma^{*}{ }_{\mathrm{H} 8-07}$ & 0.023 & $\sigma *_{\mathrm{N} 3-\mathrm{H} 6}$ & 0.019 \\
\hline $\begin{array}{l}\text { TFW }_{1} \\
\text { FW }_{2} \\
\text { TFW }_{2}\end{array}$ & $\mathrm{n}_{\mathrm{S} 1} \rightarrow$ & H8-O7 & 7.75 & $\begin{array}{l}\mathrm{n}_{\mathrm{O} 7} \\
\mathrm{n}_{\mathrm{O} 7} \\
\mathrm{n}_{\mathrm{O} 7}\end{array}$ & $\begin{array}{l}\rightarrow \sigma^{*} \mathrm{~N} 3-\mathrm{H} 6 \\
\rightarrow \sigma^{*} \mathrm{H} 5-\mathrm{N} 3 \\
\rightarrow \sigma^{*}{ }_{\mathrm{H} 5-\mathrm{N} 3}\end{array}$ & $\begin{array}{l}9.02 \\
6.65 \\
7.74\end{array}$ & $\begin{array}{l}\sigma{ }^{*}{ }_{\mathrm{H} 8-\mathrm{O} 7} \\
\sigma{ }^{*}{ }_{\mathrm{H} 5-\mathrm{N} 3} \\
\sigma{ }^{*}{ }_{\mathrm{H} 5-\mathrm{N} 3}\end{array}$ & $\begin{array}{l}0.034 \\
0.019 \\
0.026\end{array}$ & $\sigma *_{\mathrm{N} 3-\mathrm{H} 6}$ & 0.033 \\
\hline $\mathrm{FW}_{3}$ & $\mathrm{n}_{\mathrm{O} 1} \rightarrow$ & $\mathrm{H} 7-\mathrm{O} 8$ & 7.43 & & & & $\sigma^{*}{ }_{\mathrm{H} 8-\mathrm{O} 7}$ & 0.021 & & \\
\hline $\begin{array}{l}\text { TFW } \\
\text { UW }_{1} \\
\text { TUW }_{1}\end{array}$ & $\begin{array}{l}\mathrm{n}_{\mathrm{S} 1} \rightarrow \\
\mathrm{n}_{\mathrm{O} 1} \rightarrow \\
\mathrm{ns}_{1} \rightarrow\end{array}$ & $\begin{array}{l}\mathrm{H} 7-\mathrm{O} 8 \\
\mathrm{H} 9-\mathrm{O} 10 \\
\mathrm{H} 9-\mathrm{O} 10\end{array}$ & $\begin{array}{l}5.32 \\
8.32 \\
9.06\end{array}$ & $\begin{array}{l}\mathrm{n}_{\mathrm{O} 8} \\
\mathrm{n}_{\mathrm{O} 1 \mathrm{O}} \\
\mathrm{n}_{\mathrm{O} 1 \mathrm{O}}\end{array}$ & $\begin{array}{l}\rightarrow \sigma^{*}{ }_{\mathrm{H} 4-\mathrm{C} 2} \\
\rightarrow \sigma^{*} \mathrm{H7}-\mathrm{N} 3 \\
\rightarrow \sigma^{*} \mathrm{H} 7 \mathrm{~N} 3\end{array}$ & $\begin{array}{l}0.58 \\
4.94 \\
9.74\end{array}$ & $\begin{array}{c}\sigma^{*} \mathrm{H} 7-\mathrm{O} 8 \\
\sigma^{*} \mathrm{H} 9-\mathrm{O} 10 \\
\sigma^{*} \mathrm{H} 9-\mathrm{O} 10\end{array}$ & $\begin{array}{l}0.021 \\
0.026 \\
0.036\end{array}$ & $\begin{array}{l}\sigma^{*} \mathrm{H} 4-\mathrm{C} 2 \\
\sigma^{*} \mathrm{H} 7 \mathrm{~N} 4 \\
\sigma^{*}{ }_{\mathrm{H} 7-\mathrm{N} 4}\end{array}$ & $\begin{array}{l}0.043 \\
0.016 \\
0.028\end{array}$ \\
\hline $\mathbf{U W}_{2}$ & & & & $\begin{array}{l}\mathrm{n}_{\mathrm{O} 10} \\
\mathrm{n}_{\mathrm{O} 10}\end{array}$ & $\begin{array}{l}\rightarrow \sigma^{*}{ }_{\mathrm{H} 8-\mathrm{N} 4} \\
\rightarrow \sigma^{*}{ }_{\mathrm{H} 6-\mathrm{N} 3}\end{array}$ & $\begin{array}{l}1.76 \\
1.84\end{array}$ & $\begin{array}{l}\sigma * \mathrm{H} 8-\mathrm{N} 4 \\
\sigma{ }^{*} \mathrm{H} 6-\mathrm{N} 3\end{array}$ & $\begin{array}{l}0.013 \\
0.013\end{array}$ & & \\
\hline TUW $_{2}$ & & & & $\begin{array}{l}\mathrm{n}_{\mathrm{O} 1 \mathrm{O}} \\
\mathrm{n}_{\mathrm{O} 1 \mathrm{O}}\end{array}$ & $\begin{array}{l}\rightarrow \sigma^{*} \mathrm{H} 8 \mathrm{-N} 4 \\
\rightarrow \sigma^{*} \mathrm{H} 6-\mathrm{N} 3\end{array}$ & $\begin{array}{l}2.43 \\
2.37\end{array}$ & $\begin{array}{l}\sigma^{*} \mathrm{H} 8-\mathrm{N} 4 \\
\sigma^{*}{ }_{\mathrm{H} 6-\mathrm{N} 3}\end{array}$ & $\begin{array}{l}0.021 \\
0.021\end{array}$ & & \\
\hline UOW $_{1}$ & $\mathrm{n}_{\mathrm{O} 1} \rightarrow \mathrm{c}$ & H10-O11 & 17.85 & & & & $\sigma^{*} \mathrm{H} 12-\mathrm{O} 10$ & 0.046 & & \\
\hline TUSW $_{1}$ & $\mathrm{n}_{\mathrm{O} 1} \rightarrow \mathrm{c}$ & H10-O11 & 10.21 & $\mathrm{n}_{\mathrm{O} 11}$ & $\rightarrow \sigma^{*} \mathrm{H} 8 \mathrm{-N} 5$ & 15.77 & $\sigma^{*} \mathrm{H} 12-\mathrm{O} 10$ & 0.030 & $\sigma^{*}{ }_{\mathrm{H} 8-\mathrm{N} 5}$ & 0.043 \\
\hline UOW $_{2}$ & $\mathrm{n}_{\mathrm{O} 2} \rightarrow \mathrm{c}$ & H10-O11 & 1.40 & $\mathrm{n}_{\mathrm{O} 10}$ & $\rightarrow \sigma^{*} \mathrm{H} 6-\mathrm{N} 4$ & 8.02 & $\sigma^{*} \mathrm{H} 10-\mathrm{O} 11$ & 0.006 & $\sigma^{*}{ }_{\mathrm{H} 6-\mathrm{N} 4}$ & 0.024 \\
\hline TUSW $_{2}$ & & & & $\mathrm{n}_{\mathrm{O} 11}$ & $\rightarrow \sigma^{*} \mathrm{H} 6-\mathrm{N} 4$ & 8.83 & $\sigma^{*} \mathrm{H} 6-\mathrm{N} 4$ & 0.014 & & \\
\hline $\mathrm{UOW}_{3}$ & & & & $\begin{array}{l}\mathrm{n}_{\mathrm{O} 1 \mathrm{O}} \\
\mathrm{n}_{\mathrm{O} 1 \mathrm{O}}\end{array}$ & $\begin{array}{l}\rightarrow \sigma^{*} \mathrm{H7}-\mathrm{N} 4 \\
\rightarrow \sigma^{*}{ }^{*} \mathrm{H} 9 \mathrm{~N} 5\end{array}$ & $\begin{array}{l}2.98 \\
1.20\end{array}$ & $\sigma^{*} \mathrm{H} 7 \mathrm{~N} 4$ & 0.012 & $\sigma^{*}$ H9-N5 & 0.014 \\
\hline TUSW $_{3}$ & & & & $\begin{array}{l}\mathrm{n}_{\mathrm{O} 1 \mathrm{C}} \\
\mathrm{n}_{\mathrm{O} 1 \mathrm{C}}\end{array}$ & $\begin{array}{l}\rightarrow \sigma^{*} \mathrm{H7}-\mathrm{N} 4 \\
\rightarrow \sigma^{*} \mathrm{H} 9-\mathrm{N} 5\end{array}$ & $\begin{array}{l}2.47 \\
1.86\end{array}$ & $\sigma^{*} \mathrm{H} 7 \mathrm{~N} 4$ & 0.017 & $\sigma^{*}{ }_{\mathrm{H} 9-\mathrm{N} 5}$ & 0.017 \\
\hline
\end{tabular}

Intramolecular hydrogen transfer $\left(\mathbf{U O W}_{\mathbf{1}}\right) \mathrm{n}_{\mathrm{O} 1} \rightarrow \sigma^{*}{ }_{\mathrm{H} 8 \mathrm{-N} 5(6.56 \mathrm{kcal} / \mathrm{mol})},(\mathbf{U O W} \mathbf{3}) \mathrm{n}_{\mathrm{O} 1} \rightarrow \sigma^{*} \mathrm{H} 8-\mathrm{N} 5(10.41 \mathrm{kcal} / \mathrm{mol}),\left(\mathbf{T U S}_{\mathbf{3}}\right) \mathrm{n}_{\mathrm{O} 1} \rightarrow$ $\sigma{ }^{*}{ }_{\mathrm{H} 8-\mathrm{N} 5}(4.78 \mathrm{kcal} / \mathrm{mol})$

$\sigma^{*}{ }_{\mathrm{H} 10-\mathrm{O} 11}$ and $\mathrm{n}_{\mathrm{O} 11} \rightarrow \sigma^{*}{ }_{\mathrm{H} 8-\mathrm{N} 5}$ orbital interactions with $\mathrm{E}^{(2)}$ values of 10.21 and $15.77 \mathrm{kcal} / \mathrm{mol}$ strengthen the TUSW $_{1}$ adduct. The orbital interactions $\mathrm{n}_{\mathrm{O} 11} \rightarrow$ $\sigma^{*}{ }_{\mathrm{H} 6-\mathrm{N} 4}$ in $\mathbf{T U S W}_{2}, \mathrm{n}_{\mathrm{O} 2} \rightarrow \sigma^{*}{ }_{\mathrm{H} 10-\mathrm{O} 11}$ and $\mathrm{n}_{\mathrm{O} 10} \rightarrow$ $\sigma^{*}{ }_{\mathrm{H} 6-\mathrm{N} 4}$ in $\mathbf{U O W}_{2}$ have $\mathrm{E}^{(2)}$ values of $8.83,1.40$ and $8.02 \mathrm{kcal} / \mathrm{mol}$ respectively suggesting higher stabilization of $\mathbf{U O W} \mathbf{W}_{2}$ adduct. The $\mathrm{E}^{(2)}$ values in the adducts $\mathbf{U O W}_{2}, \mathbf{U O W}_{3}, \mathbf{T U S W}_{2}$, and TUSW 3 indicate that CT components are relatively lower than the respective values for $\mathbf{U O W}_{\mathbf{1}}$ and $\mathbf{T U S W} \mathbf{W}_{\mathbf{1}}$. The $\mathrm{E}^{(2)}$ values indicate that the covalent character of the hydrogen bonds in urea monoxide-water adducts follow the same order $\mathbf{U O W}_{1}>\mathbf{U O W}_{2}>\mathbf{U O W}_{3}$ as that of stabilization energies. The order of stability for adducts $\mathbf{U O W}_{\mathbf{1}}>$ $\mathbf{U W}_{1}>\mathbf{F W}_{\mathbf{1}}$ is supported by CT.

Important second order stabilization energies for the orbital interactions strengthening the formation of homodimers at B3LYP/6-311++ $\mathrm{G}^{* *}$ [L1] level are reported in table 5 . In the most stable homodimer of formamide, $\mathbf{D F}_{\mathbf{1}}$ that have two $\mathrm{N}-\mathrm{H} \cdots \mathrm{O}=\mathrm{C}$ as hydrogen bonds, $\mathrm{E}^{(2)}$ values for the orbital interactions $\mathrm{n}_{\mathrm{O} 1} \rightarrow$ $\sigma^{*}{ }_{\mathrm{H} 12-\mathrm{N} 10}$ and $\mathrm{n}_{\mathrm{O} 7} \rightarrow \sigma^{*}{ }_{\mathrm{H} 4-\mathrm{N} 3}$ is $12.02 \mathrm{kcal} / \mathrm{mol}$ each which are higher in comparison to the $\mathrm{E}^{(2)}$ values in $\mathbf{F W}_{\mathbf{1}}$. Thus the larger stability of $\mathbf{D F}_{\mathbf{1}}$ can be assigned to better CT between the monomeric units. The $\mathrm{E}^{(2)}$ values associated with orbital interactions among $\mathrm{N}$ $\mathrm{H} \cdots \mathrm{S}=\mathrm{C}$ in most stable $\mathbf{D T F} \mathbf{F}_{\mathbf{1}}$ is $11.63 \mathrm{kcal} / \mathrm{mol}$ nearly each which explains its higher stability in comparison to $\mathbf{T F W}_{\mathbf{1}}$. The $\mathrm{E}^{(2)}$ values for the orbital interactions in $\mathbf{D F}_{2}$ are $\mathrm{n}_{\mathrm{O} 1} \rightarrow \sigma *_{\mathrm{H} 9-\mathrm{C} 8}(3.56 \mathrm{kcal} / \mathrm{mol})$ and $\mathrm{n}_{\mathrm{O} 7} \rightarrow \sigma *_{\mathrm{H} 4-\mathrm{N} 3}(11.88 \mathrm{kcal} / \mathrm{mol})$ indicating higher contribution of $\mathrm{H} 4 \cdots \mathrm{O} 7$ hydrogen bond as well supported by geometrical parameters for the hydrogen bond reported in table 2. In $\mathbf{D} \mathbf{T F}_{\mathbf{2}}$, the small $\mathrm{E}^{(2)}$ values for $\mathrm{n}_{\mathrm{S} 1} \rightarrow \sigma^{*}{ }_{\mathrm{H} 9-\mathrm{C} 8}(4.98 \mathrm{kcal} / \mathrm{mol})$ supporting the weak hydrogen bond $\mathrm{S} 1 \cdots \mathrm{H} 9$ also supported by geometrical parameters. However, the second hydrogen bond has $\mathrm{n}_{\mathrm{S} 7} \rightarrow \sigma^{*}{ }_{\mathrm{H} 4-\mathrm{N} 3}$ orbital interaction that gives rise to $\mathrm{E}^{(2)}$ value of $11.12 \mathrm{kcal} / \mathrm{mol}$. The stability of $\mathbf{D F}_{\mathbf{3}}$ is more supported by orbital interaction $\mathrm{H} 5 \cdots \mathrm{O} 7$ as suggested by $\mathrm{E}^{(2)}$ value of $\mathrm{n}_{\mathrm{O} 7} \rightarrow \sigma *_{\mathrm{H} 5-\mathrm{N} 3}$ $(7.75 \mathrm{kcal} / \mathrm{mol})$ and favoured by short hydrogen bond distance and more linearity as compared to N3 . H H 12 hydrogen bond which possesses small $\mathrm{E}^{(2)}$ value of 
Table 5. Second order stabilization energies $\mathrm{E}^{(2)}(\mathrm{kcal} / \mathrm{mol})$ and occupancies of acceptor orbitals for the orbital interactions strengthening the formation of homodimers at B3LYP/6-311++G** [L1] level.

D A $\quad$ D $A$

Homodimers Monomer 1 Monomer $2 \mathrm{E}^{(2)}$ Monomer 2 Monomer $1 \mathrm{E}^{(2)} \overline{\text { Acceptor } \text { Monomer } 2 \text { Acceptor Monomer } 1}$

\begin{tabular}{|c|c|c|c|c|c|c|c|c|}
\hline $\mathbf{D F}_{1}$ & $\mathrm{n}_{\mathrm{O} 1} \rightarrow \sigma^{*} \mathrm{H} 12-\mathrm{N} 10$ & 12.02 & $\mathrm{n}_{\mathrm{O} 7} \rightarrow \sigma^{*}{ }_{\mathrm{H} 4-\mathrm{N} 3}$ & 12.02 & $\sigma *_{\mathrm{H} 12-\mathrm{N} 10}$ & 0.050 & $\sigma^{*} \mathrm{H} 4 \mathrm{-N} 3$ & 0.049 \\
\hline DTF $_{1}$ & $\mathrm{n}_{\mathrm{S} 1} \rightarrow \sigma^{*} \mathrm{H} 12-\mathrm{N} 10$ & 11.63 & $\mathrm{n}_{\mathrm{S} 7} \rightarrow \sigma^{*}{ }_{\mathrm{H} 4-\mathrm{N} 3}$ & 11.66 & $\sigma *_{\mathrm{H} 12-\mathrm{N} 10}$ & 0.047 & $\sigma^{*} \mathrm{H} 4 \mathrm{-N} 3$ & 0.047 \\
\hline $\mathbf{D F}_{2}$ & $\mathrm{n}_{\mathrm{O} 1} \rightarrow \sigma^{*}{ }_{\mathrm{H} 9-\mathrm{C} 8}$ & 3.56 & $\mathrm{n}_{\mathrm{O} 7} \rightarrow \sigma^{*}{ }_{\mathrm{H} 4-\mathrm{N} 3}$ & 11.88 & $\sigma *_{\mathrm{H} 9-\mathrm{C} 8}$ & 0.062 & $\sigma^{*} \mathrm{H} 4-\mathrm{N} 3$ & 0.044 \\
\hline DTF $_{2}$ & $\mathrm{n}_{\mathrm{S} 1} \rightarrow \sigma^{*}{ }_{\mathrm{H} 9-\mathrm{C} 8}$ & 4.98 & $\mathrm{n}_{\mathrm{S} 7} \rightarrow \sigma^{*}{ }_{\mathrm{H} 4-\mathrm{N} 3}$ & 11.12 & $\sigma *_{\mathrm{H} 9-\mathrm{C} 8}$ & 0.054 & $\sigma^{*}{ }_{\mathrm{H} 4-\mathrm{N} 3}$ & 0.055 \\
\hline $\mathbf{D F}_{3}$ & $\mathrm{n}_{\mathrm{N} 3} \rightarrow \sigma^{*}{ }_{\mathrm{H} 12-\mathrm{N} 10}$ & 1.72 & $\mathrm{n}_{\mathrm{O} 7} \rightarrow \sigma^{*}{ }_{\mathrm{H} 5-\mathrm{N} 3}$ & 7.75 & $\sigma *_{\mathrm{H} 12-\mathrm{N} 10}$ & 0.018 & $\sigma^{*} \mathrm{H} 5$-N3 & 0.035 \\
\hline DTF $_{3}$ & $\mathrm{n}_{\mathrm{N} 3} \rightarrow \sigma^{*}{ }_{\mathrm{H} 12-\mathrm{N} 10}$ & 2.30 & $\mathrm{n}_{\mathrm{S} 7} \rightarrow \sigma^{*}{ }_{\mathrm{H} 5-\mathrm{N} 3}$ & 9.70 & $\sigma *_{\mathrm{H} 12-\mathrm{N} 10}$ & 0.022 & $\sigma^{*} \mathrm{H} 5$-N3 & 0.050 \\
\hline $\begin{array}{l}\mathrm{DF}_{4} \\
\text { DTF }_{4}\end{array}$ & & & $\begin{array}{l}\mathrm{n}_{\mathrm{O} 7} \rightarrow \sigma^{*} \mathrm{H} 5-\mathrm{N} 3 \\
\mathrm{n}_{\mathrm{S} 7} \rightarrow \sigma^{*}{ }_{\mathrm{H} 5-\mathrm{N} 3}\end{array}$ & $\begin{array}{l}11.32 \\
10.37\end{array}$ & & & $\begin{array}{l}\sigma *_{\mathrm{H} 5-\mathrm{N} 3} \\
\sigma *_{\mathrm{H} 5-\mathrm{N} 3}\end{array}$ & $\begin{array}{l}0.62 \\
0.044\end{array}$ \\
\hline $\mathrm{DF}_{5}$ & $\mathrm{n}_{\mathrm{O} 1} \rightarrow \sigma^{*}{ }_{\mathrm{H} 9-\mathrm{C} 8}$ & 2.24 & $\mathrm{n}_{\mathrm{O} 7} \rightarrow \sigma^{*}{ }_{\mathrm{H} 6-\mathrm{C} 2}$ & 2.26 & $\sigma *_{\mathrm{H} 9-\mathrm{C} 8}$ & 0.060 & $\sigma^{*}{ }_{\mathrm{H} 6-\mathrm{C} 2}$ & 0.060 \\
\hline DTF $_{5}$ & $\mathrm{n}_{\mathrm{S} 1} \rightarrow \sigma^{*}{ }_{\mathrm{H} 9-\mathrm{C} 8}$ & 3.84 & $\mathrm{n}_{\mathrm{S} 7} \rightarrow \sigma *_{\mathrm{H} 6-\mathrm{C} 2}$ & 3.82 & $\sigma *_{\mathrm{H} 9-\mathrm{C} 8}$ & 0.050 & $\sigma^{*}{ }_{\mathrm{H} 6-\mathrm{C} 2}$ & 0.050 \\
\hline $\mathrm{DU}_{1}$ & $\mathrm{n}_{\mathrm{O} 1} \rightarrow \sigma^{*}{ }_{\mathrm{H} 15-\mathrm{N} 11}$ & 13.33 & $\mathrm{n}_{\mathrm{O} 9} \rightarrow \sigma *_{\mathrm{H} 5-\mathrm{N} 3}$ & 13.43 & $\sigma *_{\mathrm{H} 15-\mathrm{N} 11}$ & 0.044 & $\sigma *{ }_{\mathrm{H} 5-\mathrm{N} 3}$ & 0.045 \\
\hline DTU $_{1}$ & $\mathrm{n}_{\mathrm{S} 1} \rightarrow \sigma^{*} \mathrm{H} 15-\mathrm{N} 11$ & 17.79 & $\mathrm{n}_{\mathrm{S} 9} \rightarrow \sigma^{*}{ }_{\mathrm{H} 5-\mathrm{N} 3}$ & 17.75 & $\sigma *_{\mathrm{H} 15-\mathrm{N} 11}$ & 0.040 & $\sigma^{*} \mathrm{H} 5$-N3 & 0.040 \\
\hline $\mathbf{D U}_{2}$ & $\mathrm{n}_{\mathrm{N} 3} \rightarrow \sigma^{*} \mathrm{H} 13-\mathrm{N} 10$ & 8.90 & $\mathrm{n}_{\mathrm{O} 9} \rightarrow \sigma^{*}{ }_{\mathrm{H} 8-\mathrm{N} 4}$ & 4.27 & $\sigma *_{\mathrm{H} 13-\mathrm{N} 10}$ & 0.030 & $\sigma^{*} \mathrm{H8- \textrm {N } 4}$ & 0.029 \\
\hline $\mathbf{D T U}_{2}$ & $\mathrm{n}_{\mathrm{N} 3} \rightarrow \sigma^{*}{ }_{\mathrm{H} 13-\mathrm{N} 10}$ & 10.25 & $\mathrm{n}_{\mathrm{S} 9} \rightarrow \sigma^{*}{ }_{\mathrm{H} 8-\mathrm{N} 4}$ & 6.32 & $\sigma *_{\mathrm{H} 13-\mathrm{N} 10}$ & 0.030 & $\sigma^{*} \mathrm{H} 8-\mathrm{N} 4$ & 0.038 \\
\hline DUO $_{1}$ & $\mathrm{n}_{\mathrm{O} 1} \rightarrow \sigma^{*}{ }_{\mathrm{H} 17-\mathrm{N} 14}$ & 18.39 & & & & & $\sigma *_{\mathrm{H} 17-\mathrm{N} 14}$ & 0.063 \\
\hline DTUS $_{1}$ & $\mathrm{n}_{\mathrm{O} 1} \rightarrow \sigma^{*}{ }_{\mathrm{H} 17-\mathrm{N} 14}$ & 9.05 & & & & & $\sigma *_{\mathrm{H} 17-\mathrm{N} 14}$ & 0.045 \\
\hline
\end{tabular}

$\mathrm{n}_{\mathrm{N} 3} \rightarrow \sigma^{*}{ }_{\mathrm{H} 12-\mathrm{N} 10}(1.72 \mathrm{kcal} / \mathrm{mol})$. The $\mathrm{E}^{(2)}$ values for $\mathrm{n}_{\mathrm{S} 7} \rightarrow \sigma^{*}{ }_{\mathrm{H} 5-\mathrm{N} 3}$ orbital interactions $(9.70 \mathrm{kcal} / \mathrm{mol})$ strengthen the S7 $\cdots$ H5-N3 hydrogen bond in $\mathbf{D T F}_{3}$ in comparison to small $\mathrm{E}^{(2)}$ stabilization for $\mathrm{N} 3 \cdots \mathrm{H} 12$.

The strongly bound homodimers $\mathbf{D U}_{\mathbf{1}}$ and $\mathbf{D T} \mathbf{U}_{\mathbf{1}}$ are supported by strong $\mathrm{E}^{(2)}$ values for the two hydrogen bonds and can be seen in table 5. In $\mathbf{D} \mathbf{U}_{1}, \mathrm{CT}$ contribution arising from $\mathrm{n}_{\mathrm{O} 1} \rightarrow \sigma^{*}{ }_{\mathrm{H} 15-\mathrm{N} 11}$ and $\mathrm{n}_{\mathrm{O} 9} \rightarrow$ $\sigma^{*}{ }_{\text {H5-N3 }}$ orbital interactions with $\mathrm{E}^{(2)}$ values of 13.33 and $13.43 \mathrm{kcal} / \mathrm{mol}$ respectively. Similarly for $\mathrm{n}_{\mathrm{S} 1} \rightarrow$ $\sigma_{\mathrm{H} 15-\mathrm{N} 11}$ and $\mathrm{n}_{\mathrm{S} 9} \rightarrow \sigma^{*}{ }_{\mathrm{H} 5 \mathrm{~N} 3}$ orbital interactions in DTU $_{1}$, the $\mathrm{E}^{(2)}$ values are 17.79 and $17.75 \mathrm{kcal} / \mathrm{mol}$ respectively indicating higher stability of DTU $_{1}$ in comparison to the $\mathbf{D U}_{\mathbf{1}}$. Relatively weaker strengthening of hydrogen bond from the CT interactions occur in monohydrated adducts of urea and thiourea. As can be seen from table 5 in $\mathbf{D U O} \mathbf{O}_{1}$, the $\mathrm{E}^{(2)}$ value of orbital interactions $\mathrm{n}_{\mathrm{O} 1} \rightarrow \sigma^{*}{ }_{\mathrm{H} 17-\mathrm{N} 14}$ for the hydrogen bond $\mathrm{O} 1 \cdots \mathrm{H} 17$ is $18.39 \mathrm{kcal} / \mathrm{mol}$ suggesting its high stability as compared to $\mathbf{D T U S}_{\mathbf{1}}$ with $\mathrm{E}^{(2)}$ value of $9.05 \mathrm{kcal} / \mathrm{mol}$. From the analysis of $\mathrm{E}^{(2)}$ values, it is reflected that homodimer $\mathbf{D U O}_{1}$ is $2.46 \mathrm{kcal} / \mathrm{mol}$ more stable as compared to the most stable monohydrated adduct $\mathbf{U O W}_{\mathbf{1}}$ also supported by geometrical parameters in tables 1 and 2 whereas for other conformation of monohydrate adducts is $4.38-4.55 \mathrm{kcal} / \mathrm{mol}$ less stable.
The NBO analysis clearly states that better CT occurs between the monomers in homodimers, in comparison to the adducts with water. Important $\mathrm{E}^{(2)}$ values for the orbital interactions that are explaining conjugation in adducts with water relative to monomer evaluated at B3LYP/6-311++G** [L1] level are reported in table TS46. It is reflected that conjugation in adducts is being enhanced on adduct formation suggesting their high stability. Similar enhancement in conjugation has been observed upon homodimeric formation reported in supporting information table TS47. The increment in $\mathrm{E}^{(2)}$ values for conjugation is higher for homodimers relative to monohydrated adducts.

\section{Conclusions}

The hydrogen bonding ability of formamide, urea, urea monoxide and their thio-analogs have been analyzed by studying their adducts with water and the homodimers. The stabilization energies for the adduct between formamide, urea and urea monoxide with single water, range between $3.67-8.59 \mathrm{kcal} / \mathrm{mol}$. While similar adducts with thio-analogs have the stabilization energy in the range $2.73-4.29 \mathrm{kcal} / \mathrm{mol}$. Relatively stronger hydrogen bonds result in homodimers as 
reflected by range of stabilization energy 5.01-12.54 $\mathrm{kcal} / \mathrm{mol}$ for formamide, urea and urea monoxide and $5.63-11.48 \mathrm{kcal} / \mathrm{mol}$ for thio-analogs. The most stable adduct of formamide and urea with water has two hydrogen bonds with carbonyl oxygen and $\mathrm{N}-\mathrm{H}$ as hydrogen bond acceptor and donor respectively towards water, the most stable homodimer also adorn two hydrogen bonds with similar sites as hydrogen bond donor and hydrogen bond acceptor in each monomeric unit. But the difference in stability of the two can be assigned to better $\mathrm{CT}$ in the homodimers assisted by resonance interactions in the monomeric units as reflected by NBO analysis.

In case of thioformamide and thiourea, it is thiocarbonyl sulfur and $\mathrm{N}-\mathrm{H}$ as hydrogen bond acceptor and donor respectively. Thus, when both the sites (thiocarbonyl sulfur and $\mathrm{N}-\mathrm{H}$ ) are simultaneously involved in hydrogen bonding, it results in most stable conformation observed from the study of hydrated molecules and homodimers. The CT in the most stable conformation of homodimer is high as compared to monohydrated adducts. However in case of urea monoxide and thiourea monoxide, the most stable adducts with water involve additional oxygen and $\mathrm{N}-\mathrm{H}$ as hydrogen bond acceptor and donor, respectively. In this case, stability of the latter is higher in comparison to former, which has been rationalized in terms of two hydrogen bonds involving resonance in the six-membered cyclic structure, due to high charge density of oxygen arising from the presence of sulfur. Whereas, in their homodimer, only single hydrogen bond with additional oxygen of one monomer and $\mathrm{N}-\mathrm{H}$ of other monomer. Oxo-analog of homodimer is more stabilized relative to its thio-analog.

\section{Supplementary Information}

The optimized geometrical parameters for the adducts and corresponding monomeric units using the B3LYP and MP2 method are accessible through the supporting information tables TS1-TS22. The optimized geometrical parameters for the dimers are reported in tables TS23-TS38. The values of topological properties at BCPs characterizing the hydrogen bonds in monohydrate adducts and homodimers are reported in tables TS39-S40. The atomic charges have been evaluated using NBO analysis for all the thirty-two monohydrated adducts and homodimers reported in tables TS41-TS45. Important second order stabilization energies $\mathrm{E}^{(2)}(\mathrm{kcal} / \mathrm{mol})$ for the orbital interactions strengthening the formation of adduct with water and their homodimers reported in TS46-TS47. Molecular electrostatic potential (MEP) maps of the molecules and their adducts with water under investigation along with the $\mathrm{V}_{\max }$ and $\mathrm{V}_{\text {min }}$ values from blue to red regions respectively are reported in figure $\mathrm{S} 1$. Supplementary information is available at www.ias.ac.in/chemsci.

\section{Acknowledgement}

The authors are highly thankful to University Grants Commission (UGC) for financial assistance.

\section{References}

1. Jeffrey G A 1997 In An Introduction to Hydrogen Bonding (USA: Oxford University Press)

2. Desiraju G R and Stenier T 1999 In The Weak Hydrogen Bond (Oxford: Oxford University Press)

3. Bandhopadhyay I, Lee H M and Kim K S 2005 J. Phys. Chem. A. 1091720

4. Sobczyk L, Grabowski S and Krygowski T M 2005 Chem. Rev. 1053513

5. Hinton J F and Harpool R D 1997 J. Am. Chem. Soc. 99 349

6. Jaeisen P G and Stevens W J 1986 J. Chem. Phys. 84 3271

7. Engdahl A and Nelander B 1993 J. Chem. Phys. 994894

8. Sim F and St-Amant A 1992 J. Am. Chem. Soc. 114439

9. Wang X C, Facelli J C and Simons J 1993 Int. J. Quantum. Chem. 45123

10. Liu T, Li H, Huang M, Duan Y and Wang Z $2008 \mathrm{~J}$. Phys. Chem. A. 1125436

11. Urban J J, Tillman B G and Cronin W A 2006 J. Phys. Chem. A. 11011120

12. Pliego J R Jr 2004 Chem. Phy. 306273

13. Cordeiro M A M, Santana W P, Cusinato R and Cordeiro J M M 2006 J. Mol. Struct. (THEOCHEM) 759159

14. Sakai D, Mastuda Y, Hachiya M, Mori M, Fujii A and Mikami N 2008 J. Phys. Chem. A. 1126840

15. Del Bene J E, Alkorta I and Elguero J 2008 J. Phys. Chem. A. 1126338

16. Taha A N and True N S 2000 J. Phys. Chem. A. 1042985

17. Angelina E L and Peruchena N M 2011 J. Phys. Chem. A. 1154701

18. Espinosa E and Molins E 2000 J. Chem. Phys. 1135686

19. Sunita S S, Rohini N K, Kulkarni M G, Nagaraju M and Sastry G N 2006 J. Am. Chem. Soc. 1287752

20. Sunita S S, Rohini N K, Kulkarni M G, Nagaraju M and Sastry G N 2007 Macromolecules 401824

21. Nagaraju M and Sastry G N 2010 Int. J. Quantum. Chem. 1101994

22. Nenitescu K D 1962 In Organicheskaya Khimiya (Organic Chemistry). Izdatestvo Innostrannoy Literatury, Academician Kabachnick, MI (ed.) (Moscow: Publishing of foreign literature) Vol. $1 \mathrm{p} 815$

23. Zhang R, Zhao G and Wu W 2009 Chin. J. Chem. Phys. 22511

24. Lee K, Benson D R, and Kuczera K 2000 Biochemistry 3913737 
25. Gao J, Pavelites J J and Habibollazadeh D 1996 J. Phys. Chem. A. 1002689

26. Vishnyakov A, Lyubartsev A P and Laaksonen A 2001 J. Phys. Chem. A. 1051702

27. Finer E G, Franks F and Tait M J 1972 J. Am. Chem. Soc. 944424

28. Hoccart X and Turrel G J 1993 J. Chem. Phys. 99 8498

29. Keuleers R, Rousseau B, Alsenoy C V and Desseyn H O 1999 J. Phys. Chem. A. 103462

30. Ramondo F, Bencienni L, Caminiti R, Pieretti A and Gontrani L 2007 Phys. Chem. Chem. Phys. 92206

31. Burton R C, Ferrari E S, Davey R J, Hopwood J, Qualey M J, Finney J L and Bowron D T 2008 Cryst. Growth Des. 81559

32. Siu D and Koga Y 2005 J. Phys. Chem. B. 10916886

33. Lee M and van der Vegt N F A 2006 J. Am. Chem. Soc. 1284948

34. Fong C, Wells D, Krodkiewska I, Hartley P G and Drummond C J 2006 Chem. Mater. 18594

35. Koga Y, Miyazaki Y, Nagano Y and Inaba A $2008 J$. Phys. Chem. B. 11211341

36. Weiqn Z, Wen Y and Lihua Qiu 2005 J. Mol. Struct. (THEOCHEM) 730133

37. Vazquez L, Salvarezza R C and Arvia A 1997 J. Phys. Rev. Lett. 79709

38. Kim K, Lin Y T and Mosher H S 1988 Tetrahedron. Lett. 293183

39. Maryanoff C A, Stanzione R C, Plampin J N and Mills J E 1986 J. Org. Chem. 511882

40. Mantri P, Duffy D E and Kettner C A 1996 J. Org. Chem. 615690

41. Dempcy R O, Browne K A and Bruice T C 1995 J. Am. Chem. Soc. 1176140

42. Sigman M S and Jacobsen E N 1998 J. Am. Chem. Soc. 1204901

43. Whitesides G M and Ismagilov R F 1999 Science 28489

44. Chigwada T R and Simoyi R H 2005 J. Phys. Chem. A. 1091094

45. Gao Q Y, Liu B, Li L H and Wang J C 2007 J. Phys. Chem A. 111872

46. Miller A E, Bischoff J J and Pae K 1988 Chem. Res. Toxicol. 1169

47. Wiequn Z, Wen Y and L Qiu 2005 J. Mol. Struct. (THEOCHEM) 133

48. Peng K, Yang W and Zhou W 2009 Int. J. Quantum Chem. 109811

49. Dill K A 1990 Biochemistry 297133

50. Jeffrey G A and Saenger W 1991 In Hydrogen Bonding in Biological Structures (Berlin: Springer-Verlag)

51. Stickle D F, Presta L G, Dill K A and Rose G D 1992 J. Mol. Biol. 2261143

52. Mardyukov A, Sanchez-Garcia E, Rodziewicz P, Doltsinis N L and Sander W 2007 J. Phys. Chem. A. 111 10552

53. Frey J A and Leutwyler S 2006 J. Phys. Chem. A. 110 12512

54. Grabowski S J, Sokalski W A and Leszczynski J 2006 J. Phys. Chem. A. 1104772

55. Papmokos G V and Demetropoulos I N 2004 J. Phys. Chem. A. 1087291

56. Tsuchida E 2004 J. Chem. Phys 1214740
57. Bende A and Suhai S 2005 Int. J. Quantum Chem. 103 841

58. Varga R, Garza J, Friesner R A, Stern H, Hay B P and Dixon D A 2001 J. Phys. Chem. A. 1054963

59. Desfrancois C, Peiquet V, Carles S, Schermann J P and Andamowicz L 1998 Chem. Phys. 239475

60. Cabaleiro-Lago E M and Otero J R 2002 J. Chem. Phys. 1171621

61. Belosludov R V, Li Z and Kawazoe Y 1999 Mol. Eng. 8 105

62. Masunov A and Dannerberg J J 199 J. Phys. Chem. A. 103178

63. Wallqvist A and Karlström G 1989 Chem. Scr. A. 29 1989

64. Tanaka H, Touhara H and Nakanishi K 1985 J. Chem. Phys. 825184

65. Jakli G and van Hook W W 1981 J. Phys. Chem. 853480

66. Adams R, Balyuzi H M and Burge R E 1977 J. Appl. Crystallogr. 10256

67. Frisch M J, Trucks G W, Schlegel H B, Scuseria G E, Robb M A, Cheeseman J R, Scalmani G, Barone V, Mennucci B, Petersson G A, Nakatsuji H, Caricato M, Li X, Hratchian H P, Izmaylov A F, Bloino J, Zheng G, Sonnenberg J L, Hada M, Ehara M, Toyota K, Fukuda R, Hasegawa J, Ishida M, Nakajima T, Honda Y, Kitao O, Nakai H, Vreven T, Montgomery J A, Peralta J E, Ogliaro F, Bearpark M, Heyd J J, Brothers E, Kudin K N, Staroverov V N, Kobayashi R, Normand J, Raghavachari K, Rendel A, Burant J C, Iyengar S S, Tomasi J, Cossi M, Rega N, Millam J M, Klene M, Knox J E, Cross J B, Bakken V, Adamo C, Jaramillo C, Gomperts R, Stratmann R E, Yazyev O, Austin A J, Cammi R, Pomelli C, Ochterski J W, Martin R L, Morokuma K, Zakrzewski V G, Voth G A, Salvador P, Dannenberg J J, Dapprich S, Daniels A D, Farkas O, Foresman J B, Ortiz J V, Cioslowski J and Fox D J 2009 Exploring Chemistry with Electronic Structure Methods; Gaussian Inc.: Wallingford, CT

68. Hehre W J, Radoom L, Schleyer P V R and Pople J A 1986 In Ab Initio Molecular Orbital Theory (New York: Wiley)

69. Foresman J B and Frisch E 1996 In Exploring Chemistry with Electronic Structure Methods: A Guide to using Gaussian. (Pittsburg: Gaussian Inc.)

70. Boys S F and Bernardi F 1970 Mol. Phys. 19553

71. Merrick J P, Moran D and Radom L 2007 J. Phys. Chem. A. 11683

72. Bader R F W 1990 In Atoms in Molecules: A Quantum Theory (Oxford: Oxford University Press)

73. Biegler-König F and Schönbohm J 2002 AIM 2000 version 2.0, Germany

74. Glendening E D and Streitwieser A 1994 J. Chem. Phys. 1002900

75. Glendening E D 1996 J. Am. Chem. Soc. 1182473

76. Schenter G K and Glendening E D 1996 J. Phys. Chem. 10017152

77. Glendening E D, Badenhoop J K, Reed A E, Carpenter J E, Bohmann J A, Morales C M and Weinhold F 2001 Theoretical Chemistry Institute, University of Wisconsin, Madison

78. Weinhold F and Landis C R 2001 Chem. Edu. Res. Pract. 291 
79. Schmidt M W, Baldridge K K, Boatz J, Elbert S T, Gordon M S, Jensen J H, Koseki S, Matsunaga N, Nguyen K A, Su S J, Windus T L, Dupuis M and Montgomery Jr. J A 1993 J. Comput. Chem. 141347

80. Foster J P and Weinhold F 1980 J. Am. Chem. Soc. 102 7211

81. Reed A E and Weinhold F 1983 J. Chem. Phys. 784066
82. Koch U and Popelier P L A 1995 J. Phys. Chem. 99 9747

83. Popelier P L A 2000 In Atoms in Molecules: An Introduction (London: Pearson Education)

84. Langley C H and Allinger N L 2003 J. Phys. Chem. A. 1075208

85. Glendening E D 2005 J. Phys. Chem. A. 10911936 